\title{
Histone Modifications and Cancer
}

\author{
James E. Audia ${ }^{1}$ and Robert M. Campbell ${ }^{2}$ \\ ${ }^{1}$ Constellation Pharmaceuticals, Cambridge, Massachusetts 02142; ${ }^{2}$ Eli Lilly and Company, Lilly Corporate \\ Center, Indianapolis, Indiana 46285 \\ Correspondence:jim.audia@constellationpharma.com
}

\section{SUMMARY}

Histone posttranslational modifications represent a versatile set of epigenetic marks involved not only in dynamic cellular processes, such as transcription and DNA repair, but also in the stable maintenance of repressive chromatin. In this article, we review many of the key and newly identified histone modifications known to be deregulated in cancer and how this impacts function. The latter part of the article addresses the challenges and current status of the epigenetic drug development process as it applies to cancer therapeutics.

\section{Outline}

1 Introduction

2 Histone modifications
3 Drug-discovery challenges for histonemodifying targets

\section{References}

Editors: C. David Allis, Marie-Laure Caparros, Thomas Jenuwein, Danny Reinberg, and Monika Lachner Additional Perspectives on Epigenetics available at www.cshperspectives.org

Copyright (C 2016 Cold Spring Harbor Laboratory Press; all rights reserved; doi: 10.1101/cshperspect.a019521

Cite this article as Cold Spring Harb Perspect Biol 2016;8:a019521 


\section{OVERVIEW}

Cancer is a diverse collection of diseases characterized by the dysregulation of important pathways that control normal cellular homeostasis. This escape from normal control mechanisms leads to the six hallmarks of cancer, which include sustaining proliferative signaling, evading growth suppressors, resisting cell death, enabling replicative immortality, inducing angiogenesis, and activating invasion and metastasis (Hanahan and Weinberg 2011). The systematic investigation of the acquired and inherited molecular alterations in the genomes of somatic cells has revealed a great deal about the genetic basis for cancer initiation, progression, and maintenance. This progress has afforded a number of promising and effective opportunities for therapeutic intervention.

The epigenetic mechanisms that govern transcriptional regulation and the corresponding dysregulation in cancer, initially less well studied, have increasingly become the focus of cancer researchers, although the transgenerational effects remain largely unexplored. "Epigenetic" transcriptional control can occur through DNA methylation, covalent histone modification, the reading of these modifications by protein recognition modules, histone exchange, and alteration by ATP-dependent chromatin remodelers and via the effects of noncoding RNA. Because DNA methylation in cancer is addressed elsewhere, this article focuses on many of the covalent histone modifications that are altered in cancer, particularly the well-studied acetylation and methylation modifications.
Collectively, the combination of histone marks found in a localized region of chromatin function through multiple mechanisms as part of a "chromatin-based signaling" system (Jenuwein and Allis 2001; Schreiber and Bradley 2002). The landscape of known histone and nonhistone modifications that affect chromatin-based processes continues to expand. The diverse set of observed histone adornments includes phosphorylation, citrullination, sumoylation, adenosine diphosphate (ADP) ribosylation, deimination, and crotonylation. The various known epigenetic mechanisms work in a concerted and interdependent fashion to regulate gene expression. In cancers, their misregulation can result in the inappropriate activation of oncogenes or, conversely, the inappropriate inactivation of tumor suppressors. There is also a growing understanding and appreciation for the genetic basis contributing to epigenetic changes observed in cancer. This adds to the complexity of cancer etiology and, perhaps, offers important general insights into the epigenetic basis of human disease.

This article speaks of some of the challenges faced by the epigenetic drug discovery process, searching for molecules targeting epigenetic regulators and also supporting an emerging role of epigenetic alterations that occur during chemotherapy, thought to contribute to drug resistance. Finally, it highlights some of the more recent progress toward developing therapeutic agents in this promising target space. 


\section{INTRODUCTION}

DNA within cells is packaged as chromatin, a dynamic structure composed of nucleosomes as the fundamental building blocks. Histones are the central component of the nucleosomal subunit, forming an octamer containing the four core histone proteins $(\mathrm{H} 3, \mathrm{H} 4, \mathrm{H} 2 \mathrm{~A}, \mathrm{H} 2 \mathrm{~B})$ around which is wrapped a 147-base-pair segment of DNA. Each of the largely globular histone proteins possesses a characteristic side chain, or tail, which is densely populated with basic lysine and arginine residues. The histone tails are subject to extensive covalent posttranslational modifications (PTMs) that cooperate to govern the chromatin state. Some PTMs can alter the charge density between histones and DNA, impacting chromatin organization and underlying transcriptional processes, but they can also serve as recognition modules for specific binding proteins that, when bound, may then signal for alterations in chromatin structure or function.

Alterations in the patterns of histone PTMs have been extensively linked to cancer, both at the global level across the genome (Seligson et al. 2005; Bannister and Kouzarides 2011) and at specific gene loci, using ChIP-chip (chromatin immunoprecipitation with DNA microarray analysis) and ChIP-sequencing (parallel sequencing technologies coupled to chromatin immunoprecipitation) technology. These findings have come on the back of the earlier, more established findings linking aberrant DNA methylation to cancer, discovered in the early 1980s (see Baylin and Jones 2014). In addition to recent PTM mapping projects, sequencing efforts have also now identified many of the enzymes responsible for placing ("writers") and removing ("erasers") such epigenetic marks (Fig. 1). Mutations in such enzymes turn out to be among the most frequently mutated targets in cancers (Shen and Laird 2013). Collectively, these findings show interplay between cancer genetics and epigenetics, adding to the complexity in our understanding of the oncogenic process. Advances in whole genome/exome sequencing of patient tumors have allowed for the identification of possible key epigenetic drivers of cancer. These epigenetic drivers may silence one or more tumor-suppressor genes and/or activate oncogenes, thus providing an alternative mechanism by which oncogenic reprogramming of the genome may occur (Shen and Laird 2013). Genomic studies have clearly implicated dysregulation of chromatin modifiers as drivers in many types of cancer (Garraway and Lander 2013) and recurrent mutations occur in the genes that encode the enzymes, which add, remove, and interpret the covalent histone modifications. Intriguingly, certain chromatin

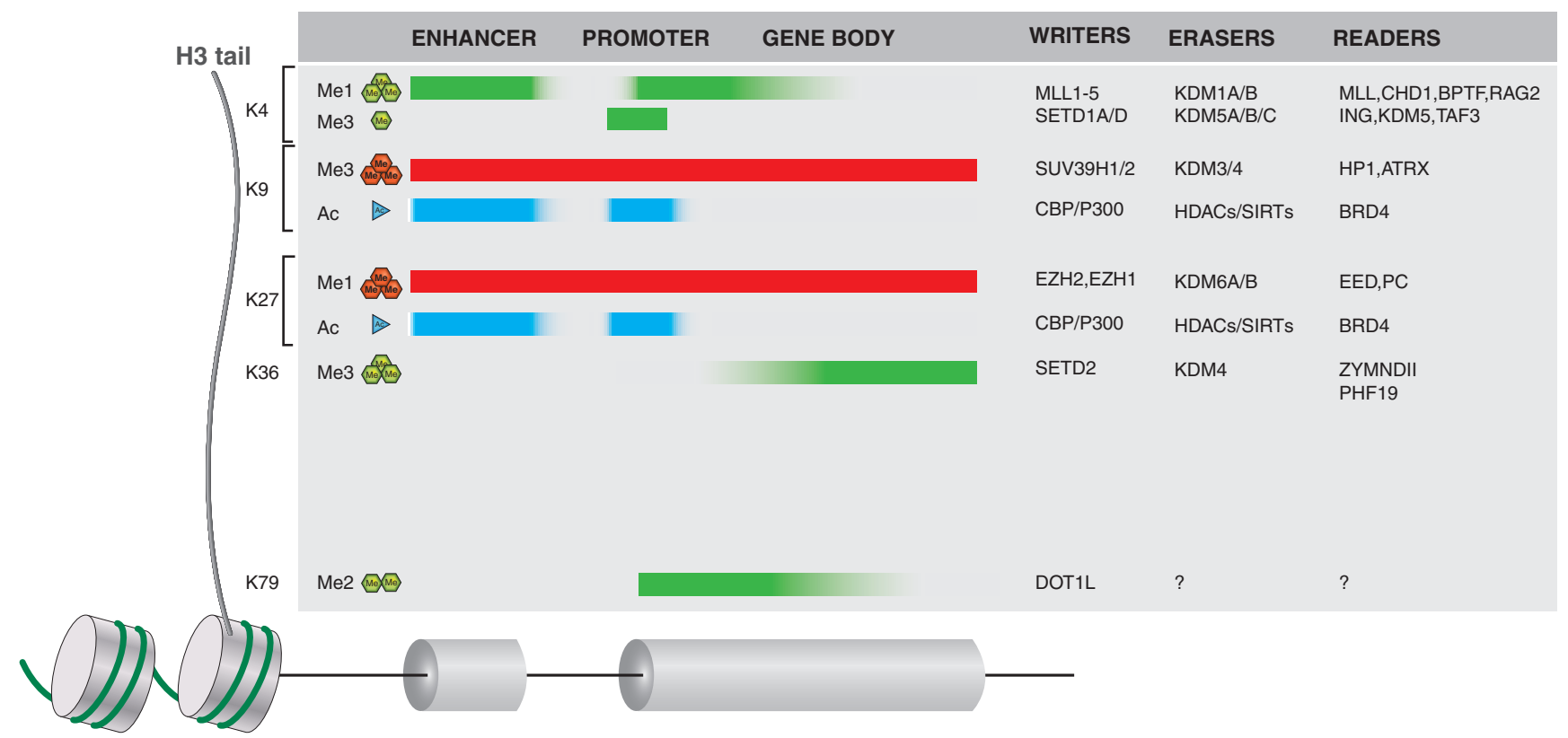

Figure 1. Histone writers, erasers, and readers in cancer. Histone $\mathrm{H} 3$ tail lysine residues, frequently subject to posttranslational modifications (PTMs), are indicated along the left side. The typical distribution of these H3 PTMs is also indicated along the length of gene loci (including distal enhancers) as shaded blocks. Green (methylation) or cyan (acetylation) indicates histone marks associated with active genes, whereas red shading is indicative of silent genes. A few examples of writers, erasers, and readers that may propagate a mark or act as an effector protein are listed on the right side of the figure. For a more complete listing of these proteins, see Appendices A-D at the end of this article. 
modifiers have been identified in cancer, for both increased and decreased levels of functionality, suggesting they operate both as tumor-suppressor genes and oncogenes. The loss-of-function mutations in affected tumors are often heterozygous, suggesting that haploinsufficiency for these chromatin-modifying enzymes drives the cancer, whereas total absence of function is cell lethal. As a result, this class of enzymes has broad appeal as potential therapeutic targets with both gain-of-function aberrations associated with oncogenic behavior and monoallelic loss-of-function changes rendering tumor cells particularly vulnerable to further inhibition.

An additional level of epigenetic control, and with it additional complexity, is brought by the wide variety of proteins that act at the chromatin level through domains that "read" histone and even DNA PTMs. Direct aberrations in reader proteins have recently been shown to drive oncogenic transformation in some contexts (French et al. 2001, 2008). The discovery of potent and selective smallmolecule inhibitors of prototypic members of readers from the bromodomain family, which recognize acetyllysine marks, suggests that these may represent attractive points of therapeutic intervention in cancers arising from other genetic and epigenetic drivers (elaborated in Qi 2014; Schaefer 2014; also see Filippakopoulos et al. 2010; Gallenkamp et al. 2014). In summary, the ensemble of chromatin regulators and adaptors possess a diverse set of specialized domains that serve to bind to and recognize histone modifications either individually or in specific combinations. These protein-binding modules play an important role in directing the appropriate transcriptional machinery to locations on chromatin.

This article focuses on highlighting what is known about the well-studied PTMs in cancer. Recent findings on some newer PTMs also illustrate the pace of progress in the field and serve to highlight the complexity of the epigenome, its regulation and dysregulation in cancer, and the nature of its regulators and interacting proteins. The second part of this article instructs the reader about the drug-discovery process as it applies to the search for effective therapeutics that interfere with epigenetic targets or reverse epigenetic adaptions contributing to drug resistance during cancer treatment.

\section{HISTONE MODIFICATIONS}

It is well noted that PTM of histones mediates a variety of critical biological processes, generally via chromatin modification that is conducive to the expression or repression of target genes. The bulk of the literature has focused on acetylation, methylation, and phosphorylation. However, in addition to these well-published modifications, histones may also be modified in other ways, some of which are illustrated in Figure 6 of Allis et al. (2014) or included in Zhao and Garcia (2014). These include citrullination, ubiquitination, ADP-ribosylation, deamination, formylation, O-GlcNAcylation, propionylation, butyrylation, crotonylation, and proline isomerization (Chen et al. 2007; Martin and Zhang 2007; Ruthenburg et al. 2007; Tan et al. 2011; Herranz et al. 2012; Tweedie-Cullen et al. 2012). It is generally accepted that the sum of all these PTMs largely determines the chromatin structure and, hence, biological outcome. The contextual reading and interpretation of the collection of histone modifications is critical, as the same combination of marks may result in distinct biologic outcomes at different genes within the same (or different) cells. This may, at least in part, be due to different reader recognition, DNA-binding proteins, and/or chromatin conformations. Experimentally, the modification and the reader cannot be readily separated for a specific output, and this is an important limitation of our current ability to readily translate combinatorial PTMs. Furthermore, the enzymes that modulate the addition or removal of these moieties are not fully understood (see Cheng 2014; Marmorstein and Zhou 2014; Seto and Yoshida 2014) or, in many cases, yet to be identified.

\subsection{Histone Acetylation}

The addition of an acetyl group can occur at multiple lysine residues on histone tails. This has the potential to broadly influence the compaction state of chromatin by neutralizing the basic charge at unmodified lysine residues (Kouzarides 2007), weakening the electrostatic interaction between negatively charged DNA and histones. An increasing body of data, however, suggests that this may be an oversimplification of the consequences of this modification and likely belies the importance of specific acetylation events. Another recently discovered, generalized function of histone acetylation may be to regulate intracellular $\mathrm{pH}$ (pHi) (McBrian et al. 2013); this is corroborated by the fact that many tumors show low pHi and display concomitant reduced levels of histone acetylation, which correlates with a poor clinical outcome. From a functional perspective, we know that histone acetylation is largely associated with active transcription, particularly localized at enhancers, promoters, and the gene body (Di Cerbo and Schneider 2013). Altered global levels of histone acetylation, particularly acetylation of $\mathrm{H} 4$ at lysine $(\mathrm{K}) 16$, have been linked to a cancer phenotype in a variety of cancers (Fraga et al. 2005) and have even been found to be of potential prognostic value (Seligson et al. 2009). When hyperacetylation occurs, specifically involving proto-oncogenes, gene expression may be activated, whereas hypoacetylation of tumor sup- 
pressors often localizes to promoters, co-occurring with DNA methylation, causing the genes to be silenced (see Baylin and Jones 2014).

The enzymes that catalyze the addition of acetyl groups to histone lysine residues are the lysine $(\mathrm{K})$ acetyltransferases (KATs), commonly referred to as histone acetyltransferases (HATs). These enzymes can also acetylate a broad range of nonhistone proteins, including $\mathrm{p} 53, \mathrm{Rb}$, and MYC. The opposing histone deacetylases (HDACs) are responsible for their removal. Although HATs are generally associated with transcriptional activity, both HAT and HDAC activity together are required for properly regulated gene expression (Struhl 1998). This is partly to do with their activity often being an integral part of multisubunit chromatin-modifying complexes. As a result, genetic or epigenetic aberrations affecting HAT and HDAC expression, translation, protein stability, or domain function can have chromatin regulatory consequences beyond changes in the histone acetylation states. In addition to the structural effects acetylation has on chromatin, it can also function in chromatin as a signal that is recognized by a specific protein module (i.e., "reader"), such as the bromodomain. Epigenetic-based drugs, targeting acetyl readers, are thus likely to be of clinical relevance in the treatment of cancer. Given that acetylation modifications are reversible, the pharmacological intervention of HATs, HDACs, and acetyllysine readers represent known, in the case of HDACs, or viable strategies of therapeutic value in the treatment of cancer.

\subsubsection{Histone Acetylation Writers}

In humans, there are three major families of HATs: the Gcn5-related $N$-acetyltransferase family (GNAT), the MYST family (MOZ, Ybf2, Sas2, TIP60), and the orphan family (CBP/EP300 and nuclear receptors), whose structure and mechanism of action are elaborated in Marmorstein and Zhou (2014). A variety of studies have implicated HATs as both oncogenes and tumor suppressors, suggesting that the balance of acetylation is critical. Many of the HAT mutations frequently detected in a variety of cancers are captured in Appendix A at the end of this article (Di Cerbo and Schneider 2013). Interestingly, alterations in HAT levels, both upward (Chen et al. 2012b; Hou et al. 2012) and downward (Seligson et al. 2009), often occur without DNA mutation in cancers and are associated with poor outcome.

Somatic mutations in a single allele of the p300 and CBP genes have been identified in multiple cancers. The resulting loss of heterozygosity implicates them as tumor suppressors (Muraoka et al. 1996; Gayther et al. 2000; for more on the characterization of tumor-suppressor genes, see Baylin and Jones 2014). It is increasingly evident that
CBP and/or EP300 are important in cancers (e.g., transgenic mice deficient in CBP or EP300 can develop hematologic malignancies [Iyer et al. 2004]). Another facet of HAT function revealed by the many mutations in CBP and EP300 is the protein's ability to acetylate the nonhistone transcription factors, p53 and BCL6; a lack of P53 and BCL6 acetylation abrogates their transcriptional activator and repressor functions (Fig. 7A of Busslinger and Tarakhovsky 2014), making the resultant cells more tumorigenic via altered pathways that tolerate DNA damage yet evade apoptosis and cell-cycle arrest (Pasqualucci et al. 2011).

Enhanced HAT activity, conversely, has an overall oncogenic effect in cancers and usually occurs as the result of chromosomal translocations with diverse fusion partners, such as mixed lineage leukemia (MLL)-CBP, MLL-EP300, MOZ-EP300, or MOZ-CBP in hematological malignancies (Krivtsov and Armstrong 2007). The oncogenic effect arises when the translocations generate chimeric oncoproteins. This may allow HATs to abnormally acetylate the genomic targets of its fusion partner. Another mechanism by which HATs, such as EP300/CBP, are oncogenic is when they are recruited by more common fusion proteins, such as acute myloid leukemia (AML)1-ETO, to serve as transcriptional coactivators (Wang et al. 2011). Overall, a HAT's oncogenic or tumor-suppressor effects in cancer are dependent on its dose; overexpression correlates with oncogenic potential, whereas loss of expression results in loss of acetylation capacity. This, therefore, suggests that HATs could be a good drug target, although, to date, progress toward producing a viable HAT inhibitor has lagged behind the development of inhibitors of its counterpart enzyme, HDACs, described in the following section.

\subsubsection{Histone Acetylation Erasers}

Alterations in HDACs, the enzymes that remove acetyl groups from histone lysine residues, have been observed in cancer. There are four major families of HDACs, termed class I, II, III, and IV. Class I, II, and IV are $\mathrm{Zn}^{2+}$-dependent, whereas class III/Sirtuins are nicotinamide adenine dinucleotide (NAD)-dependent (see Fig. 1 in Seto and Yoshida 2014). The contributions of specific HDAC subtypes to individual cancers are currently not fully understood (see Appendix B at the end of the article) (Barneda-Zahonero and Parra 2012). This may be, in part, because of the relatively low substrate specificity shown by the HDACs themselves; each individual enzyme is capable of deacetylating multiple divergent histone sites. Interestingly, mutations in HDACs are rare, but overexpression of HDACs is frequently observed in cancer patients (Dell'Aversana et al. 2012). 
The class I HDACs that are misregulated, usually by overexpression or mistargeting, are found in a variety of human cancers. The frequency with which they are deregulated in cancer, perhaps, reflects their normal function in such a wide range of tissues, but in cancer, this is often associated with poor prognosis (Nakagawa et al. 2007). The role of HDACs in cancer, as with HATs, may not be confined to histones. The growing list of reported HDAC targets that become deacetylated include $\alpha$-tubulin, HSP90 and cortactin (HDAC6), p53 (HDAC5), and ERR $\alpha$ (HDAC8); HDACs also directly act on proteins involved in tumor migration, metastasis, and growth (see Appendix B at the end of the article). The example of HDAC2 in lung cancer is a case in point; HDAC2 directly deacetylates p53 and the $\mathrm{CDKN} 1 \mathrm{~B} / 1 \mathrm{C} / 2 \mathrm{~A}$ proteins, attenuating a cell's ability to activate the apoptotic machinery or regulate cell cycle (Jung et al. 2012; Reichert et al. 2012). This, therefore, makes it hard to dissect what the exact epigenetic effects of HDAC deregulation are, and thus how HDAC inhibitors interfere with their activity.

Another mode by which HDACs are implicated in cancer is through the abnormal recruitment of HDAC-containing complexes to promoters as a consequence of chromosomal translocation, observed in leukemias (Mercurio et al. 2010). For example, the promyelocytic leukemia (PML)-retinoic acid receptor $\alpha(\mathrm{RAR} \alpha)$ translocation, which is the driver for many acute promyelocytic leukemia cases, represses many RAR target genes by the aberrant recruitment of the N-CoR/HDAC repressor complexes (Minucci and Pelicci 2006).

The class III HDACs, the Sirtuins (SIRT1-7), are also capable of deacetylating a combination of histones (SIRT1$3,6,7$ ) and nonhistone proteins (SIRT1-3, 5, 7), as well as ADP-ribosylating (SIRT4), and desuccinylating various proteins (SIRT5) (see Appendix B at the end of the article). They are distinguished from the other classes of HDACs by a distinct catalytic mechanism of action (Seto and Yoshida 2014). The bulk of efforts has focused on studying SIRT1, but has, to date, failed to clarify whether SIRT1 is a tumor suppressor or oncogene, suggesting that these activities may be contextual (Stunkel and Campbell 2011). SIRT1 is overexpressed in many tumors (leukemia, lymphoma, prostate, liver, breast, ovarian, gastric, colorectal, and melanoma) but significantly reduced in others (bladder, colon, glioma). It may be that SIRT1 plays an oncogenic role by inactivating other tumor suppressors (e.g., HIC1) and/or activating tumor promoting genes (e.g., through N-Myc stabilization, or $\mathrm{p} 53$ ) or other proteins (cortactin).

SIRT1 levels are elevated in drug-resistant SK-N-SH neuroblastoma cells, a result that prompted the evaluation of class I/II (Vorinostat) and class III (Cambinol) HDAC inhibitors in animal models of neuroblastoma (Lautz et al.
2012). In neuroblastoma, N-Myc induces SIRT1 transcription, which, in turn, enhances N-Myc stability in a feedforward loop. It is believed that SIRT1 represses MKP3 phosphatase, leading to elevated ERK phosphorylation/ activation and then to N-Myc phosphorylation, a more stable form of N-Myc. The antitumor efficacy of cambinol, a SIRT1/2 inhibitor, in both wild-type and doxorubicinresistant neuroblastoma is consistent with a tumor-promoting role for SIRT1 and/or SIRT2. Gene silencing and use of pharmacological inhibitors in MCF7 breast tumor cells indicate that blockade of both SIRT1 and SIRT2 may be required to induce apoptosis. Other dual SIRT1/2 inhibitors have shown efficacy in xenograft models (melanoma, Burkitt's lymphoma). In genetically engineered mouse models, SIRT1/PTEN-null transgenic mice spontaneously develop aggressive prostate and thyroid carcinomas. In

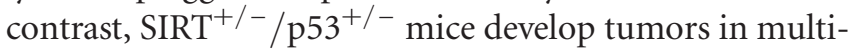
ple organs and SIRT-null mice form prostatic intraepithelial neoplasia.

SIRT3-5 are localized primarily to the mitochondria (although SIRT3 has been reported to deacetylate histones) and can modify a number of substrates involved in energy metabolism via deacetylation, ADP-ribosylation, or desuccinnylation (see Appendix B at the end of the article). It is believed that these Sirtuins act as metabolic sensors to adjust mitochondrial energy production during stress or energy deprivation (Haigis and Sinclair 2010). SIRT3, and perhaps also SIRT6, have been identified as tumor suppressors that regulate glycolysis in tumor cell (Haigis et al. 2012; Sebastian et al. 2012), with reduced expression in human breast cancer tissue versus normal. Its loss correlates with hypoxia-induced factor (HIF) $\alpha$ stabilization, up-regulation of HIF1 $\alpha$ target genes, increased glycolysis, tumor cell proliferation, and fibroblast transformation (Bell et al. 2011), whereas overexpression has the opposite effect (Finley et al. 2011; Sebastian et al. 2012). Similarly, depletion of SIRT6 leads to tumorigenesis, with transformed SIRT6-deficient MEFs displaying increased glycolysis and tumor growth. Conditional SIRT6 knockout in vivo increases the number, size, and aggressiveness of tumors. These data suggest that SIRT6 plays a role in both the establishment and maintenance of cancer (Sebastian et al. 2012).

SIRT7 deacetylates H3K18 and is highly expressed in many cancers (see Appendix A at the end of the article) (Van Damme et al. 2012; Paredes et al. 2014). Hypoacetylation of H3K18, which is indicative of high SIRT7 activity, causes tumor-suppressor gene repression, and is associated with cancer progression and poor prognosis (Seligson et al. 2005; Barber et al. 2012; Paredes et al. 2014).

Broad-spectrum (class I/II) HDAC (e.g., vorinostat, romidepsin) and DNA methylation inhibitors (Dacogen, 
Vidaza) were the first types of epigenetically targeted therapies approved by the FDA for the treatment of hematological malignancies (discussed in more depth in Baylin and Jones 2014). Data are evolving that suggest that these therapies may be even more effective in combination with standards of care or even with each other (e.g., HDACi + DNA methylation inhibitor), and perhaps be used to ameliorate chemoresistance (discussed further in Sec. 3.1). However, it is abundantly clear that the functions of each specific HDAC isoform are much more complicated and different than anticipated. This is, in part, due to their contextual function in various protein complexes and ability to modify both histone and nonhistone proteins. In the near future, it is expected that more HDAC isoform-specific small molecules (especially inhibitors) will emerge to provide more clarity as to the roles of each HDAC in tumorigenesis and the therapeutic value of more advanced HDAC modulators.

\subsubsection{Histone Acetylation Readers}

Proteins that read histone acetylated lysines can do so via the bromodomain motif. There are more than 40 bromodomain-containing proteins, which share a high level of sequence homology and structural similarity within the domain. The bromodomain was the first histone-binding module and, consequently, is the most prominent and thoroughly studied histone recognition domain. It is intrinsic to a number of histone-modifying writers (e.g., p300 and MLL) and remodelers (e.g., SMARCA2), as well as other proteins associated with chromatin function and transcriptional control. Its occurrence in such a vast array of chromatin-associating proteins has made it an obvious druggable motif in the search for new epigenetic drugs. The primary structural feature of the bromodomain is a hydrophobic acetyllysine-binding pocket surrounding, most typically, an asparagine residue, which engages in a hydrogen-bonding interaction with the modified histone substrate (for details, see Fig. 6 of Marmorstein and Zhou 2014).

The BET (bromodomain and extraterminal domain) subset of bromodomain proteins consists of four family members, BRD2, BRD3, BRD4, and BRDT, with a common architecture and structural design. BRD4 is a protein that, when bound to acetylated histones, can activate transcription (see Sec. 6 of Busslinger and Tarakhovsky 2014). The reversal of cancer cell phenotype (i.e., the promotion of differentiation and growth impairment using bromodomain-specific inhibitors, such as JQ1 and I-BET) provided the first proof of concept that this histone mark reader could act as a potential therapeutic target for the treatment of cancers, such as leukemias (described in Qi 2014; Schae- fer 2014). The inhibitors were effectively shown to phenocopy BRD4 small hairpin RNA knockdown experiments. These approaches were applied to murine MLL-AF9/ NRas ${ }^{\text {G12D }}$ leukemia models, MLL-fusion cancer cell lines, and patient-derived cells, leading to differentiation and growth impairment (Fig. 2A) (Dawson et al. 2011; Zuber et al. 2011). Further testing of the effects of selective BET inhibitors in other cancer models continues to reinforce the notion that BET proteins are potential therapeutic targets in other cancers, including nuclear protein in testis (NUT)midline carcinoma, multiple myeloma, lymphoma, lung cancer, and neuroblastoma (Delmore et al. 2011; Mertz et al. 2011; Lockwood et al. 2012; Wyce et al. 2013). The NUT-midline carcinoma, for example, has a translocation, which fuses the BRD3 or 4 protein to the NUT transcriptional regulator. This fusion produces an oncoprotein that, through binding to acetylated histones, is thought to promote transcription of proliferation genes (e.g., MYC). Although work on BET inhibitors continues to be the main focus of research, it is interesting that a dual-drug strategy involving HDAC inhibitors coupled to the JQ1 BET inhibitor has shown positive results as a therapeutic approach for the treatment of AML (Fiskus et al. 2014).

BRD7 and, more recently, BRD9 bromodomain proteins have been identified as components of chromatinremodeling switch/sucrose nonfermenting (SWI/SNF) complexes, increasingly found to be mutated in a variety of human cancers (Kaeser et al. 2008; Kadoch et al. 2013). BRD7 has specifically been linked to the control of p53 and BRCA1 transcriptional pathways (Drost et al. 2010; Harte et al. 2010). In the case of p53, BRD7 is thought to help recruit the P300 HAT to p53 target genes, activating transcription of senescence genes (Drost et al. 2010). In the case of estrogen receptor (ER)- $\alpha$ response genes, BRD7 is believed to function in the recruitment of the BRCA1 transcriptional activator (Harte et al. 2010).

CBP and EP300, previously described in the context of their HAT activity, also possess bromodomains and transcription factor binding domains. These multifunctional proteins are critical as mediators of histone marks at transcriptional enhancers (Fig. 1) (elaborated in Pirrotta 2014) and required for transcriptional activation. This is illustrated by the loss of expression at MYB target genes, controlling the proliferation and differentiation of hematopoietic stem and progenitor cells, because MYB is mutated at its P300 interacting domain and thus is no longer able to activate gene expression (Sandberg et al. 2005). It should be noted that transcriptional activation occurs in a three-dimensional context, in which looping together of enhancer and promoter regions is thought to ensure proper expression. This relies on correct local histone signatures written by HATs and lysine methyltransferases (KMTs) to facilitate 

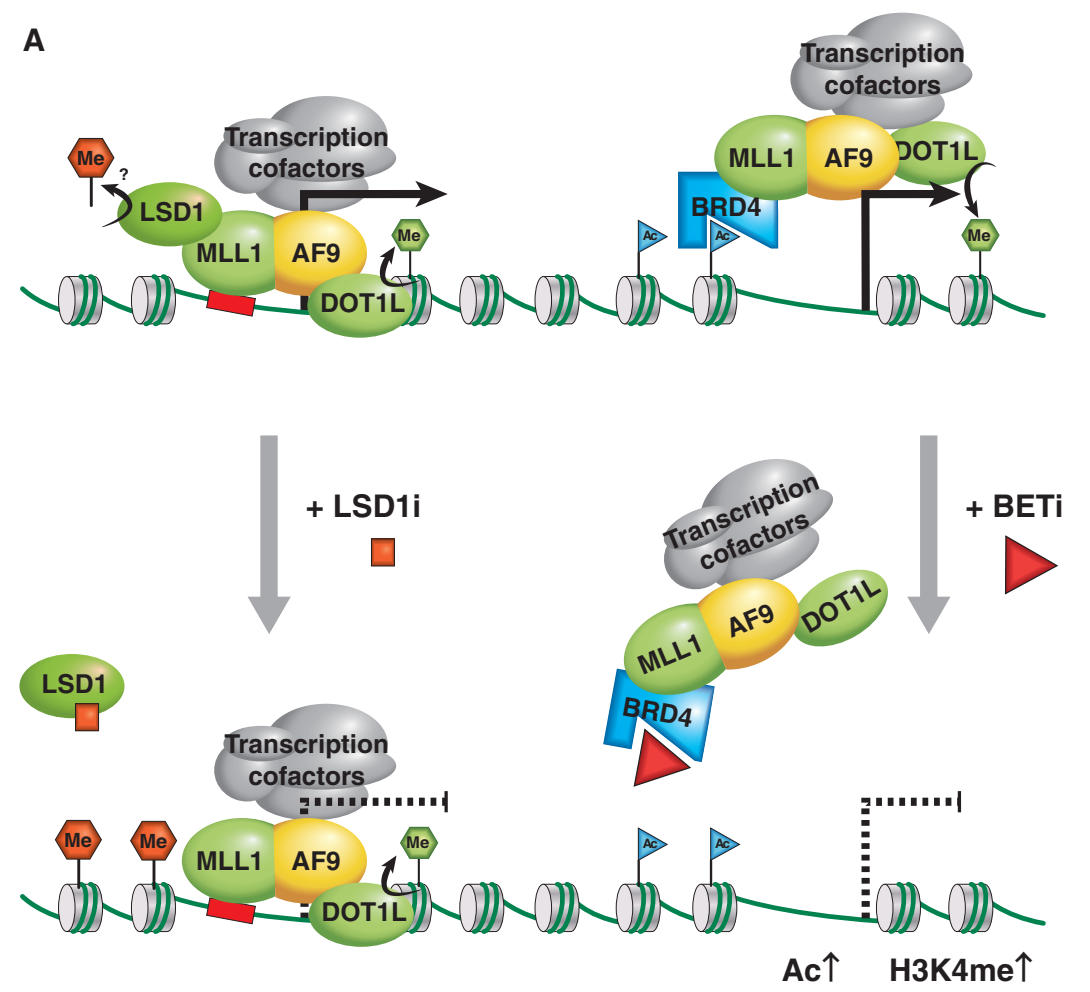

B

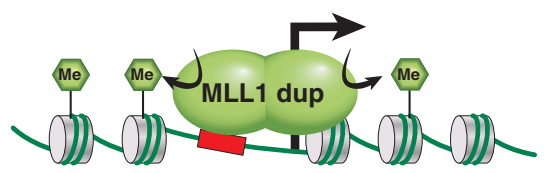

Figure 2. MLL as an oncogene. (A) The MLL1-AF9 (or ENL) fusion oncoprotein activates transcription via two possible mechanisms; the left mechanism attributes recruitment of MLL1-AF9 to chromatin via the MLL1 portion, and transcription is activated via association with cofactors, including the DOT1 methyltransferase, methylating H3K79 (green hexagon) and the pTEFb complex, which modifies RNA Polymerase II into the active elongating form. (B) The partial duplication of an MLL gene can result in duplication of an internal region that includes chromatin binding features and protein-protein interaction domains, providing oncogenic methyltransferase $\mathrm{H} 3 \mathrm{~K} 4 \mathrm{me} 3 \mathrm{ac}-$ tivity and increased transcriptional activation. LSD1 may be involved via the MLL supercomplex, or a transcription elongation complex contributing to oncogenic activity through $\mathrm{H} 4 \mathrm{~K} 4 \mathrm{me} 2$ or $\mathrm{H} 3 \mathrm{~K} 9 \mathrm{me} 2$ demethylase activity. LSD1 inhibition somehow reduces the oncogenic program, promoting differentiation. In the mechanism on the right, recruitment of MLL1-AF9 to chromatin is attributed to its association with BRD-2, -3 , or -4 via acetylated chromatin. This mechanism of gene activation can therapeutically be targeted via treatment with BET inhibitors.

an open chromatin structure and the recruitment of the full transcription machinery (Fig. 1), often through histone PTM reader proteins, such as BRD4 (reviewed in Ong and Corces 2011; exemplified in Fig. 1 of Qi 2014).

P300 was also found to mark binding sites of leukemic fusion proteins, such as AML1-ETO and PML-RAR $\alpha$, and to directly acetylate AML1-ETO fusion proteins, indicating it may have particular importance in contributing to oncogenic transcriptional programs in leukemia (Wang et al. 2011; Saeed et al. 2012). The specific function of the bromodomains in this context has not been definitively shown, but the recent identification of potent and selective chemical probe molecules should afford a similar opportunity to interrogate the function of these domains as has occurred for the BET proteins (Jennings et al. 2014). One would anticipate that, by virtue of BRD proteins being involved in multiple complexes, their mutation must have far-reaching oncogenic effects.

\subsection{Histone Methylation}

Methylation of lysine and arginine residues on histone tails represents a complex and more subtle chromatin modification than does acetylation. Multiple methylation states exist for both lysine and arginine residues, but when modified, they retain their fundamental basic character (Bannister and Kouzarides 2011). The suggestion that individual methylation states for each histone lysine or argi- 
nine can be meaningfully recognized generates enormous functional complexity. This modification is tightly regulated by a number of methyltransferase writers and demethylase eraser enzymes that act in concert to place and remove specific methyl marks critical for gene expression, cell fate, and genomic stability. Individual methyltransferases are highly specific with regard to both the lysine residue on which they operate and the degree of methylation. Appendix $\mathrm{C}$ at the end of this article captures some of the important information about lysine and arginine methyltransferases in cancer. Appendix D at the end of this article summarizes some of the important demethylases implicated in cancer. It is important to note that, whereas many of the methyltransferases and demethylases are amplified, overexpressed, deleted, misregulated, rearranged, or mutated, their direct causality on cancer as a result of changes to lysine methylation has not been broadly shown (Black et al. 2012). Additionally, cancer associations have been observed both for elevations and reductions in histone methylation (illustrated in Fig. 7 of Busslinger and Tarakhovsky 2014). The literature has much more on histone KMTs, as elaborated in this section, partly because of their earlier discovery. Discussion of protein arginine methyltransferases (PRMTs) in cancer is discussed in Section 1.4 on PTM cross talk and further in Cheng (2014).

\subsubsection{Histone H3K4 Writers}

The MLL family of KMTs is implicated in many forms of cancer, either by loss of function or, in the case of MLL1, through dysregulation following translocation or rearrangement (see Appendix $\mathrm{C}$ at the end of this article). Members of the MLL (KMT2) methyltransferases specifically methylate histone $\mathrm{H} 3$ at lysine 4. MLL1 is frequently translocated in myeloid and lymphoid leukemias, in which such rearrangements account for $\sim 80 \%$ of infant leukemias and $5 \%-10 \%$ of adult leukemias (Smith et al. 2011; Zhang et al. 2012a; Li et al. 2013a). The MLL1 fusion proteins generally do not retain the catalytic SET methyltransferase domain, but do retain their DNA-binding motifs that target Hox genes. The chimeric proteins inappropriately recruit epigenetic factors to MLL targets, altering the transcriptional control of critical genes, such as HOXA9. Constitutive HOXA9 expression prevents differentiation in myeloid lineages, thus, contributing to the maintenance of a multipotent phenotype. The fusion partners also frequently play a role in transcriptional elongation at the target genes. The partial duplication of MLL1's set KMT domain further corroborates a role for MLL1 in cancer, showing in this case, increased HoxA gene expression associated with increased $\mathrm{H} 3 \mathrm{~K} 4 \mathrm{me} 3$ marks at the promoter, albeit by an unknown mechanism (Fig. 2B) (Dorrance et al. 2006). In the case of MLL2/3 loss-of-function mutations, the molecular consequences are, at present, unclear, although increasing evidence suggests that cancers may alter H3K4 methylation states as a common method of achieving a growth advantage.

\subsubsection{Histone Lysine Erasers}

LSD1 (KDM1A) was the first reported lysine demethylase (KDM) enzyme specific to H3K4 and H3K9 residues (Shi and Tsukada 2013). It is a classic oncogene, based on the numerous reports of its overexpression in many types of cancer (see Appendix D at the end of this article). This overexpression, coupled with the fact that LSD1 is part of the MLL supercomplex and found at MLL target genes in MLL-fusion instances of AML, implicates it in the oncogenic gene expression program of these leukemia stem cells. Promising results have been obtained using a small molecule inhibitor of LSD1 in both human and murine AML cell lines with the MLL-AF9 translocation, in which induction of differentiation of otherwise proliferative undifferentiated tumor cells was observed (Fig. 2A) (Harris et al. 2012). The similar use of an LSD1 inhibitor in PML-RARa translocated AML, but this time in combination with all-trans-retinoic acid (ATRA), produced a superior antileukemic effect to the single-agent approach (Schenk et al. 2012). ATRA alone can enhance differentiation of tumor cells through the dissociation of RAR $\alpha$-recruited repressor complexes at RAR $\alpha$ target genes. The combination therapy of LSD1 inhibitor plus ATRA caused ATRA-insensitive cancer cells (i.e., a drug-resistant population) to become differentiated. Although these two results show great therapeutic promise, the mechanism by which LSD1 modulates expression is not clear at present.

Apart from KDM1 (i.e., LSD1 and -2), all the other known KDMs are members of the larger JmjC domain family of demethylases. The characterization of many of these proteins is in progress through both functional studies and the development of small molecule inhibitors targeted against them and stand to be invaluable for our understanding and treatment of cancer. One interesting finding made by Sharma et al. (2010) was the discovery of an underlying epigenetic basis for transient and reversible drug resistance that develops in certain cancer cell populations during treatment with cancer drugs. The H3K4-specific JmjC domain demethylase, KDM5A, in particular, was implicated in the development of drug resistance. Further research should be able to confirm whether epigenetic mechanisms, such as histone demethylation truly represent a broad and adaptive mechanism by which cancer cells can avoid eradication during chemotherapy (Sharma et al. 2010). The related KDM5B has also been 
associated with divergent roles in cancer: in metastatic melanoma, it has a putative tumor-suppressive function (Roesch et al. 2006; Roesch et al. 2008); in breast cancer, a proproliferative role (Mitra et al. 2011); and in prostate cancer, overexpression has been observed.

$\mathrm{H} 3 \mathrm{~K} 9$ is another histone residue in which methylation is aberrantly regulated in multiple cancers. This could be explained by alterations in $\mathrm{H} 3 \mathrm{~K} 9$-specific KMTs or opposing KDM enzymes (see Appendices $C$ and D). With respect to the G9a KMT, both deletion or lowered expression and increased expression have been observed in cancer (see Appendix $\mathrm{C}$ at the end of this article). For H3K9specific demethylases, KDM3A and KDM4 are often amplified or highly expressed, whereas attenuated expression of KDM4A has been observed in cancer (see Appendix D at the end of this article). One mechanism by which KDM3 and KDM4 could become overexpressed is by the targeted gene-activating effect of the HIF, itself induced by tumorigenic hypoxic conditions.

\subsubsection{Histone H3K27 Writers and Erasers}

EZH2 is the catalytic component of the Polycomb repressive complex 2 (PRC2) responsible for the di- and trimethylation of H3K27 (H3K27me2 and -me3) via its SET domain. EZH2 was among the earliest methyltransferase to have putative oncogenic capabilities because it was shown to be overexpressed or amplified in multiple cancers, including breast, prostate, and bladder (Bracken et al. 2003). More recently, altered EZH2 functionality was reported as oncogenic. Intriguingly, it is also believed to act as a tumor suppressor in some cancers, suggesting the balance of resulting H3K27 methylation is key.

Change-of-function mutations within the SET domain of EZH2 are oncogenic, giving rise to $\mathrm{H} 3 \mathrm{~K} 27 \mathrm{me} 3$ accumulation. Such mutations modify EZH2's H3K27 substrate preference, increasing catalytic activity at $\mathrm{H} 3 \mathrm{~K} 27 \mathrm{me} 2$ substrates (not increased for $\mathrm{H} 3 \mathrm{~K} 27 \mathrm{mel}$ substrates vs. wild type) (see Appendix $\mathrm{C}$ at the end of the article). These heterozygous oncogenic gain-of-function mutations strongly implicate the catalytic activity in the malignant transformation process, and support consequent gene silencing as being the driver for genesis or maintenance of tumor cells. Moreover, diffuse large B-cell lymphoma tumors harboring such EZH2 mutations are extremely sensitive to EZH2 inhibition with small molecule inhibitors, suggesting promise for their clinical translation and offering a path toward molecular stratification of patients on the basis of the mutational status. More compelling evidence that accumulation of H3K27me3 is central to EZH2's oncogenic effect in medulloblastoma is that EZH2 overexpression or amplification was found to be mutually exclusive to inactivating mutations in the reversing $\mathrm{H} 3 \mathrm{~K} 27$ demethylase UTX (KDM6A) (Robinson et al. 2012).

A potential tumor-suppressor role for $\mathrm{EZH} 2$, or $\mathrm{PRC} 2$, has been shown by loss-of-function mutations in myeloid malignancies (Khan et al. 2013). This was further supported by the observation that a K27M point mutation in the histone $\mathrm{H} 3$ gene $(\mathrm{H} 3 \mathrm{~F} 3 \mathrm{~A})$ in pediatric glioblastoma resulted in lowered or absent H3K27me3 (Venneti et al. 2013). This indicated that a loss of a lysine residue at position 27 of $\mathrm{H} 3$ abrogated the capacity for chromatin to appropriately repress PRC2-mediated gene expression. EZH2's repressive effects are not only modulated by the opposing UTX demethylase, but also by the activity of the SWI/SNF chromatin-remodeling complex. SWI/SNF, in fact, critically depends on EZH2 activity, as shown in cell lines and mouse models in which inactivation of EZH2 blocked tumor formation driven by SNF5 loss (Wilson et al. 2010). Collectively, these results indicate that correct genomic and developmental gene repression programs are largely ensured by H3K27 methylation. The writers and erasers of this modification, as well as other epigenetic modulators, are central to maintaining the balance of $\mathrm{H} 3 \mathrm{~K} 27$ methylation and represent viable drug-discovery targets in cancer. It is interesting to note that continued endeavors to epigenomically map cancers are suggesting that the correct balance of H3K27 methylation may be affected by other chromatin PTMs, namely DNA methylation in cancer, but also the interplay with other histone PTMs, such as acetylation (see Pirrotta 2014).

\subsubsection{Other Histone Lysine Writers and Erasers}

H3K36-specific methyltransferase writers are implicated in a variety of cancers (see Appendix $C$ at the end of this article). These enzymes are members of the NSD (nuclear receptor-binding SET domain) family (i.e., KMT3B/3F/ 3G). In AML, NSD1 (KMT3B) is fused to nucleoporin 98 (NUP98), resulting in enhanced H3K36me3 at critical HOXA gene loci, accompanied by increased transcription (Wang et al. 2007). The loss of gene repression may partly be achieved by NSD1/H3K36me3 preventing PRC2 complex access. Similarly, NSD2 (WHSC1, KMT3G) is translocated in $20 \%$ of multiple myelomas and has been reported to act as a potent coactivator of NF- $\kappa \beta$, which plays an important role in cancer progression. The investigators suggest that NSD2 is recruited to NF- $\kappa \beta$ target gene promoters on pathway induction, resulting in an elevation of histone H3K36me2 and H3K36me3 marks at their promoters, directly implicating NSD2 methyltransferase activity in gene deregulation (Yang et al. 2012).

Another common site of histone lysine methylation is at $\mathrm{H} 4 \mathrm{~K} 20$, which when monomethylated (H4K20me1) is as- 
sociated with transcriptional repression and when dimethylated (H4K20me2) is linked to DNA repair pathways. The presence of H4K20me3, accompanied by the loss of H4K16 acetylation, constitutes a common H4 cancer "epigenetic signature" predominantly at DNA repetitive sequences (Fraga et al. 2005). This suggests that one or more of the known histone H4K20 methyltransferasesthat is, SUV420H1 and SUV420H2 (H4K20me2 and H4K20me3) or SETD8 (HK20me1) (KMT5A)—could be targets for disruption in cancer cells.

\section{3 "Atypical" Histone Modifications}

The growing base of knowledge regarding some of these less prevalent or newer PTMs, namely, histone deamination/ citrullination, ubiquitination, ADP-ribosylation, deamination, N6-formylation, and O-GlcNAcylation, are discussed below.

\subsubsection{Histone Arginine Citrullination}

Histone arginine residues may become methylated like lysines, and this modification is catalyzed by the PRMT family of enzymes. Histone arginine residues, unmodified or monomethylated, may also be modified by hydrolysis to Citrulline, a process termed citrullination or deimination. This removes the positive charge, as does histone acetylation, and is enzymatically catalyzed by the partitioning and anchoring domain (PADs or PADIs). Of the PAD family, only PAD 4 has a nuclear localization signal and been clearly shown to deiminate/citrullinate histones $\mathrm{H} 3$ (Arg residues 2, 8, 17, 26), H2A, H4 (Arg3), and H1R54 (Wang et al. 2004; Tanikawa et al. 2012; Christophorou et al. 2014), although a recent report showed PAD2 as deiminating H3R26 (Zhang et al. 2012b). The citrullination of histone tails is associated with the decondensation of chromatin, but this is tightly regulated to occur only in naïve pluripotent (i.e., embryonic stem or inner cell mass cells) cells, conducive to the transcriptional activation of key stem-cell genes, or in myeloid lineages as part of the immune response to inflammatory stimuli. The $\mathrm{H} 1$-specific deimination at stem-cell loci seems to be one mechanism by which PAD4 effects chromatin decondensation through the weakening and eventual displacement of $\mathrm{H} 1$ on chromatin in ground-state pluripotent cells (Christophorou et al. 2014). Citrullination of H3R8, in some instances, may also contribute to chromatin decondensation, possibly through the interference of HP1a binding to H3K9me3 (Sharma et al. 2012). Given that PAD4 is highly expressed in many tumor tissues and cell lines (e.g., non-small-cell lung carcinoma [NSCLC], ovarian, breast, and hepatocellular carcinomas) compared with normal tissues or more-benign hyperplas- tic tissues (Chang et al. 2009), it will be interesting to see whether PAD4 contributes to tumorigenesis. It is conceivable that this may occur by promoting chromatin decondensation, resulting in the activation of pluripotent stem cell genes, or interference of HP1b heterochromatin, or via its gene-repressive effect via involvement in the p53 pathway described below.

Citrullination may have a gene-repressive effect, reported first in conjunction with HDAC1-mediated histone deacetylation of estrogen-regulated genes (Cuthbert et al. 2004; Wang et al. 2004; Denis et al. 2009). Depletion of PAD4 in colorectal tumor cells has an antitumorigenic effect, increasing the expression of p53 target genes ( $\mathrm{p} 21$, GADD45, PUMA) and inducing cell-cycle arrest and apoptosis ( $\mathrm{Li}$ et al. 2008). As p53 and PAD4 directly interact, it is not certain whether PAD4 acts in these cells via a scaffolding effect, enzymatic deiminase activity, or a combination of both.

Based on the accumulated evidence, there is interest in developing inhibitors of PADs (especially PAD2 and PAD4) for the treatment of cancer, and possibly also inflammatory diseases. Currently, PAD inhibitors are in early preclinical development, so more time will be required to understand the therapeutic potential of these targeted epigenetic therapies.

\subsubsection{Histone Lysine ADP-Ribosylation}

During the cell cycle, DNA is being damaged and repaired by an elaborate set of mechanisms that have evolved to conserve genomic integrity. Although cancers may result from improper/incomplete DNA repair, targeted inhibition of DNA repair mechanisms may also be exploited to kill cancer cells. One clinical paradigm is to interfere with the tumor's ability to repair its DNA following treatment with a cytotoxic chemotherapy (i.e., chemosensitization).

ADP-ribosylation of lysine residues is a relatively rare histone modification, occurring in $<1 \%$ of all histone proteins, but is observed particularly in instances of singleDNA-strand breaks (Boulikas 1989). Some of the NAD ${ }^{+}$. dependent Poly(ADP-ribose) polymerases (PARPs), more recently referred to as ADP-ribosyltransferases (ART), ADP-ribosylate histone and nonhistone proteins, as do some of the Sirtuins (Stunkel and Campbell 2011). PARP1 (ARTD1), the best-characterized histone ADP-ribosylating enzyme, is activated by environmental stresses, such as DNA damage, and has been reported to ADP-ribosylate the amino-terminal tails of all core histones, specifically at H2AK13, H2BK30, H3K27, H3K37, and H4K16 (Messner et al. 2010). This PTM is thought to cause chromatin decondensation and recruit DNA repair machinery. 
Interestingly, acetylation of H4K16 inhibits ADP-ribosylation by PARP1 (Messner et al. 2010). This is the first direct piece of evidence pointing to PTM cross talk between lysine ADP-ribosyl and acetylation marks. Interestingly, a group of macrodomain-containing proteins have been shown as mono-ADP-ribosylhydrolases and define a class of enzymes that renders mono-ADP-ribosylation a reversible modification (Rosenthal et al. 2013).

Responding to DNA damage repair is crucial for maintaining genomic stability and, typically, tumors are deficient in a DNA repair pathway. It is still early for deciphering a functional understanding of the biological role of histone ADP-ribosylation and individual PARP enzymes in chromatin function. Nonetheless, observed histone ADP-ribosylation and PARP1 detected during DNA repair has led to the use of PARP1 inhibitors in the treatment of breast and ovarian cancers. PARP1 inhibitors (olaparib) induce synthetic lethality (i.e., when two or more mutations together cause cell lethality) in cancer cells already mutated for BRCA1 or -2 genes. The BRCA proteins are essential components of the double-strand break (DSB) repair pathway through homologous recombination (discussed in Sec. 1.4.3), and in their absence, cancer cells become reliant on PARP1-dependent DNA repair pathways. Thus, the use of PARP1 inhibitors in BRCA mutant cancers results in tumor cell death, whereas normal cells survive owing to their still-intact BRCA1-dependent DNA damage repair pathway.

The positive progression of several PARP inhibitors through clinical trials (breast, colorectal, and ovarian cancers), although yet unapproved, lends credence to a parallel clinical approach with histone ADP-ribosylation inhibitors.

\subsubsection{Other Histone PTMs with Implications in Cancer}

A relatively new entry to histone PTMs is histone lysine deamination. This PTM already appears to play a known role in cancer progression and metastasis via genetic studies of its writing enzyme, lysyl oxidase-like 2 enzyme (LOXL2). Histone H3K4me3 can be deaminated by LOXL2 and this enzymatic activity is required to silence the tumor-suppressor gene, $\mathrm{CDH} 1$, and induce the epithelial to mesenchymal transition, commonly associated with metastasis, in breast tumor cells (Herranz et al. 2012).

N6-formylation of histone lysine residues is one of the rarest histone PTMs, found at very low abundancy $(0.04 \%-0.1 \%$ of all lysines in acid-soluble chromatin proteins) (Jiang et al. 2007). The linker histone $\mathrm{H} 1$ is $N$-formylated most frequently (13 residues), but core histones also contain multiple sites of Lys formylation (19 sites in total for H2A, H2B, H3, and H4) (Jiang et al. 2007;
Wisniewski et al. 2008). Lysine formylation increases during oxidative stress (Jiang et al. 2007), which has been associated with various disease states, including cancer. The biological relevance of N6-lysine histone formylation may lie in its potential to disrupt gene expression mediated by other histone lysine marks. For example, $\mathrm{N}$ formylation is observed at $\mathrm{H} 3 \mathrm{~K} 79$, which could possibly interfere with methylation at that site catalyzed by DOT1L, a target that has been linked to MLL-rearranged leukemias. However, specific cross talk between lysine $N$-formylation and acetylation or methylation remains unverified and there is no clear disease linkage established with histone formylation.

Histone PTM is not restricted to Arg and Lys residues. Histone Ser or Thr phosphorylation has long been known to be an important PTM involved in the cellular response to DNA damage (Rossetto et al. 2012). For example, H2A.X is phosphorylated at Ser 139 shortly after DNA damage, demarcating the region of chromatin around the DNA lesion.

Recently, $\mathrm{O}$-GlcNAcylation (addition of $\beta-\mathrm{N}$-acetylglucosamine) of Ser and Thr residues on core histones H2A at Thr101, H2B at Ser36, and H4 at Ser47 was reported, although more residues are thought to be subject to this modification (Sakabe et al. 2010). This PTM increases during heat shock and the mitotic phase of the cell cycle. The known sites of $O$-GlcNAcylation are also modified by phosphorylation, the latter of which are potentially important for H2A-H2B dimerization. This suggests that $O-$ GlcNAcylation may interfere with residues that are potentially to be phosphorylated, hence, explaining the observed increase in chromatin condensation when the O-GlcNAc transferase (OGT) enzyme is overexpressed or O-GlcNAcylation is triggered following heat shock (Hanover 2010). Thus, the increase in histone $O$-GlcNAcylation during heat shock, concurrent with DNA condensation, suggests a possible role in DNA damage.

Recently, OGT was found to operate in a ten eleven translocation (TET)2-dependent manner, particularly at transcriptional start sites. This suggests there is a combinatorial effect of DNA 5-hydroxymethylation and O-GlyNAcylation in regulating gene expression (Chen et al. 2013). Collectively, these findings suggest a possible role in transcriptional regulation, DNA damage, and thus cancer, particularly, given that the OGT partner, TET2, is a known tumor suppressor involved in myeloproliferative diseases (see Baylin and Jones 2014).

\subsection{Cross Talk among Histone Modifications}

As noted above, histones can be decorated with a wide variety of PTMs, presenting numerous combinatorial pat- 
terns (Jenuwein and Allis 2001). These can occur on any of the four core histones in the histone octamer (two copies each of histones $\mathrm{H} 2 \mathrm{~A}, \mathrm{H} 2 \mathrm{~B}, \mathrm{H} 3$, and $\mathrm{H} 4$ ) and may even differ between tails of the same histone within a nucleosome or between nucleosomes (Fig. 3) (Ruthenburg et al. 2007). There is no doubt that PTMs are implicated in cancer. Although single marks have been generalized as activating (e.g., $\mathrm{H} 3 \mathrm{~K} 9 \mathrm{ac}, \mathrm{H} 3 \mathrm{~K} 4 \mathrm{me} 3)$ or repressive (H3K9me3, H3K27me3) (Ruthenburg et al. 2007; Zhu et al. 2013), it is clear that certain PTMs can affect the ability of other marks to either be put down or read (more extensively reviewed by Ruthenburg et al. 2007; Suganuma and Workman 2008). Extracting which are the important modifications that drive tumorigenesis versus which are passengers is a key endeavor for the field. It is complicated by the fact that multiple interactions occur between PTMs, often referred to as cross talk. A few examples that have a bearing on our understanding of the epigenetic role in cancer are described in this section.

INTRAHISTONE

A

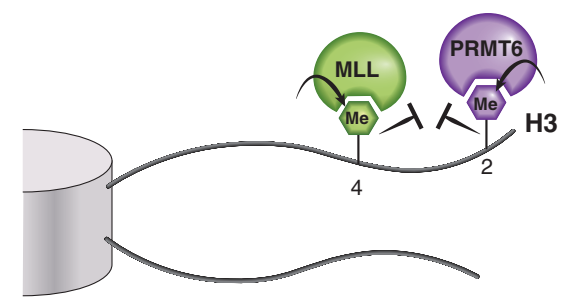

C

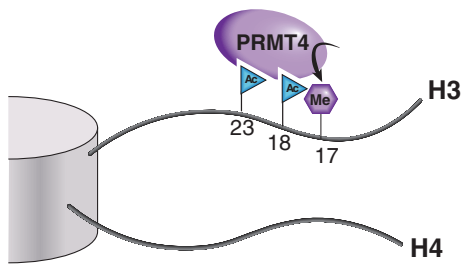

D

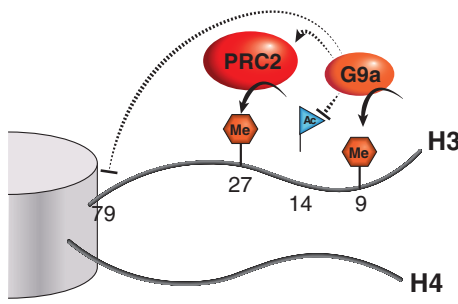

\subsubsection{Histone Lysine and Arginine Methylation Cross Talk}

There are instances in which histone PTMs can act as exclusion marks, preventing the occurrence of other marks and/or binding of chromatin readers (Migliori et al. 2010). For instance, the presence of H3K4me3 appears to inhibit the deposition of the H3R2me2a mark by PRMT6 (Guccione et al. 2007; Hyllus et al. 2007). Conversely, the H3R2me2a mark prevents methylation of H3K4 by an MLL complex, making the coexistence of these marks mutually exclusive (Fig. 3A). Another example of exclusion marks is seen when PRMT7 promotes symmetric dimethylation of H4R3 (H4R3me2s) and inhibits expression of MLL2-dependent target genes (Dhar et al. 2012). PRMT7 knockdown causes an increase in MLL2catalyzed H3K4 methylation, suggesting an inverse relationship between these methylation sites. It has been hypothesized that the H4R3me2s mark may block binding

NTERHISTONE

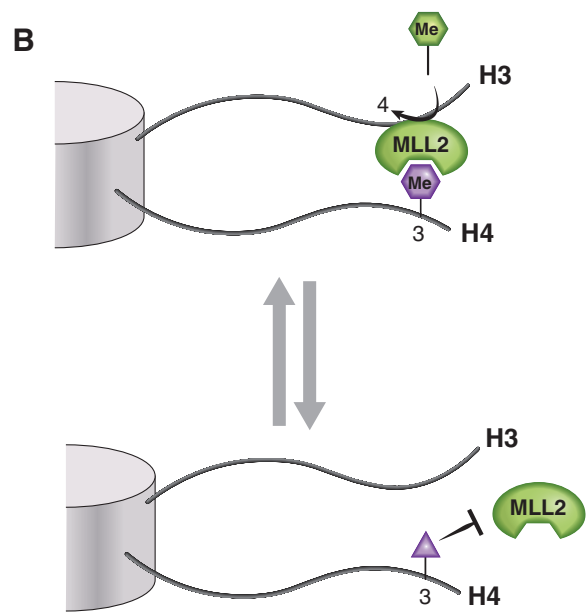

Figure 3. Histone tail cross talk. (A) H3R2me2a and H3K4 methylation are examples of mutually exclusive intrahistone H3 PTMs. (B) An example of an interhistone cross talk is when H4R3me0 or H4R3me2a marks (purple hexagon) are converted into H4R3me2s (purple triangle), which is thought to block the binding of MLL2 via its PHD4-6 domain, thus preventing the methyltransferase activity of MLL2 at H3K4. (C) PRMT4, a histone arginine methyltransferase, is thought to partially rely on $\mathrm{H} 3$ acetylation at $\mathrm{K} 18$ and $\mathrm{K} 23$ for recruitment to $\mathrm{H} 3$ and subsequent dimethylation of the nearby R17 residue. $(D)$ An illustration of the increasingly complex picture of histone $\mathrm{H} 3$ tail cross talk, involving H3K9, H3K27, and H3K79 methylation and H3K14 acetylation. See text for a more detailed explanation. 
by tandem PHD4-6 reader domain(s) within MLL2, which normally recognize $\mathrm{H} 4 \mathrm{R} 3 \mathrm{me} 0$ or $\mathrm{H} 4 \mathrm{R} 3 \mathrm{me} 2 \mathrm{a}$, and are required for its methyltransferase activity (Fig. 3B) (Dhar et al. 2012). In this way, the tails of two histones, H3 and $\mathrm{H} 4$, could interact contextually to dictate target gene expression.

\subsubsection{Cis Histone Cross Talk}

Histone lysine acetylation and arginine methylation can also act cooperatively to localize and activate other methyltransferases. A sequential process has been proposed in which estrogen stimulation, CBP/EP300, first acetylates H3K18, then H3K23, and, finally, PRMT4 is attracted to the histone tail in which it dimethylates H3R17 (Daujat et al. 2002). In vitro histone $\mathrm{H} 3 \mathrm{~K} 18 / \mathrm{K} 23$ acetylation was shown to tether recombinant PRMT4 to the $\mathrm{H} 3$ tail to efficiently catalyze arginine dimethylation (Fig. 3C) and activate estrogen-dependent genes.

Histone methylation and phosphorylation can interact in a regulatory fashion. One key example is when chromodomain recognition of a methylated lysine can be disrupted by an adjacent phosphorylation event. $\mathrm{H} 3 \mathrm{~K} 9 \mathrm{me} 3 \mathrm{is} \mathrm{im}-$ portant for recruiting heterochromatin protein 1 (HP1) to distinct chromosomal regions, required for heterochromatin formation, and thereby regulating gene expression (Stewart et al. 2005). H3 serine 10 phosphorylation adjacent to the trimethylated $\mathrm{H} 3$ (H3K9me3S10ph) by Aurora $\mathrm{B}$ causes dissociation of HP1 from heterochromatin during $\mathrm{M}$ phase and allows for mitotic progression (Fischle et al. 2005; Hirota et al. 2005). This apparently occurs by a disruption of the chromodomain binding of HP1 to H3K9me3 (see Fig. 12 of Allis et al. 2014).

With the advent of modern mass spectrometry and corresponding analytical tools, the entire panoply of histone marks may be interrogated simultaneously from cell extracts. An example is provided by the mass spectrometric analysis of HEK293 cells when G9a/GLP-1 (EHMT1/ EHMT2) is knocked down, revealing not only a reduction in the expected methyltransferase products, $\mathrm{H} 3 \mathrm{~K} 9 \mathrm{me} 1$ and H3K9me2 (H3K9me2 being predominant), but also an increase in $\mathrm{H} 3 \mathrm{~K} 79 \mathrm{me}$, a mark associated with gene expression, added by DOT1L (Plazas-Mayorca et al. 2010). In addition, the greatest reduction in $\mathrm{H} 3 \mathrm{~K} 9 \mathrm{me} 2$ was seen on peptides containing H3K14 acetylation. The biological significance of these mark changes is unknown, but it infers cross talk between G9a/GLP-1, H3K9me2, H3K79me2, and $\mathrm{H} 3 \mathrm{~K} 14 \mathrm{ac}$ (Fig. 3D). It is conceivable that H3K9me2 and $\mathrm{H} 3 \mathrm{~K} 14 \mathrm{ac}$ are mutually exclusive marks representing a form of conditional epigenetic switch. The situation is further complicated by PRC2 recruitment being shown as dependent on G9a and GLP-1 association, affecting, therefore, the degree of H3K27me3 at target genes, which mediates gene silencing (Mozzetta et al. 2014). This shows that there is additional interplay between $\mathrm{H} 3 \mathrm{~K} 27 \mathrm{me} 3$ and H3K9 methylation, which are both typically repressive marks.

Ultimately, the challenge of relating changes in primary chromatin definitively to cancer, and then determining how cross talk contributes to cancer are key questions in the field. A clear understanding of these marks is limited both by the technologies available with which to interrogate this, as well as our ability to interpret the role that the readers themselves play on the biologic output of chromatin modifications.

\subsubsection{DNA Damage Repair: Ubiquitination and Other Cross-Talking PTMs}

The repair of DNA damage is an essential cellular function, requiring a rapid dynamic response. It is important to note that repair has to occur in a chromatin context and involves extensive chromatin remodeling. The loss of total repair functionality is cell lethal; however, in cancer, there is often partial loss of function that is accompanied by an increase in genomic instability and mutation rates. PTMs of histone proteins around the DNA damage site and recruited repair proteins is a central means by which the process is regulated. In fact, our current knowledge of mammalian DNA repair in a chromatin context, illustrates the central involvement of histone PTMs as signals in the recruitment or binding inhibition of repair proteins, involving extensive cross talk. Ubiquitination, in particular, represents one of the first key modifications activating the repair pathway. Ubiquitination occurs at histone lysine residues, as do the already discussed acetylation and methylation modifications.

One of the earliest stages of the DNA damage response is when H2AX undergoes monoubiquitination at Lys119/ Lys120, mediated by the RNF2-BMI1 complex (components of the PRC1 complex). This is necessary for the recruitment of early sensors of DNA damage. They include the ATM protein, which phosphorylates histone variant H2AX to form $\gamma$-H2AX, MRN complex at broken DNA ends, and MDC1 (Fig. 4B) (Ginjala et al. 2011; Pan et al. 2011; reviewed in Panier and Durocher 2013). As RNF2BMI1 complex-depleted cells have an impaired DNA repair capability and increased sensitivity to ionizing radiation (Pan et al. 2011), it is tempting to speculate that pharmacological inhibitors of H2AX monoubiquitination may act as radio-sensitizing agents in cancer. Monoubiquitination of H2A at Lys119, incidentally, is also involved in transcriptional repression via PRC proteins, such as the RING1A and 1B ubiquitin ligases (de Napoles et al. 2004; Fang 
A Undamaged chromatin
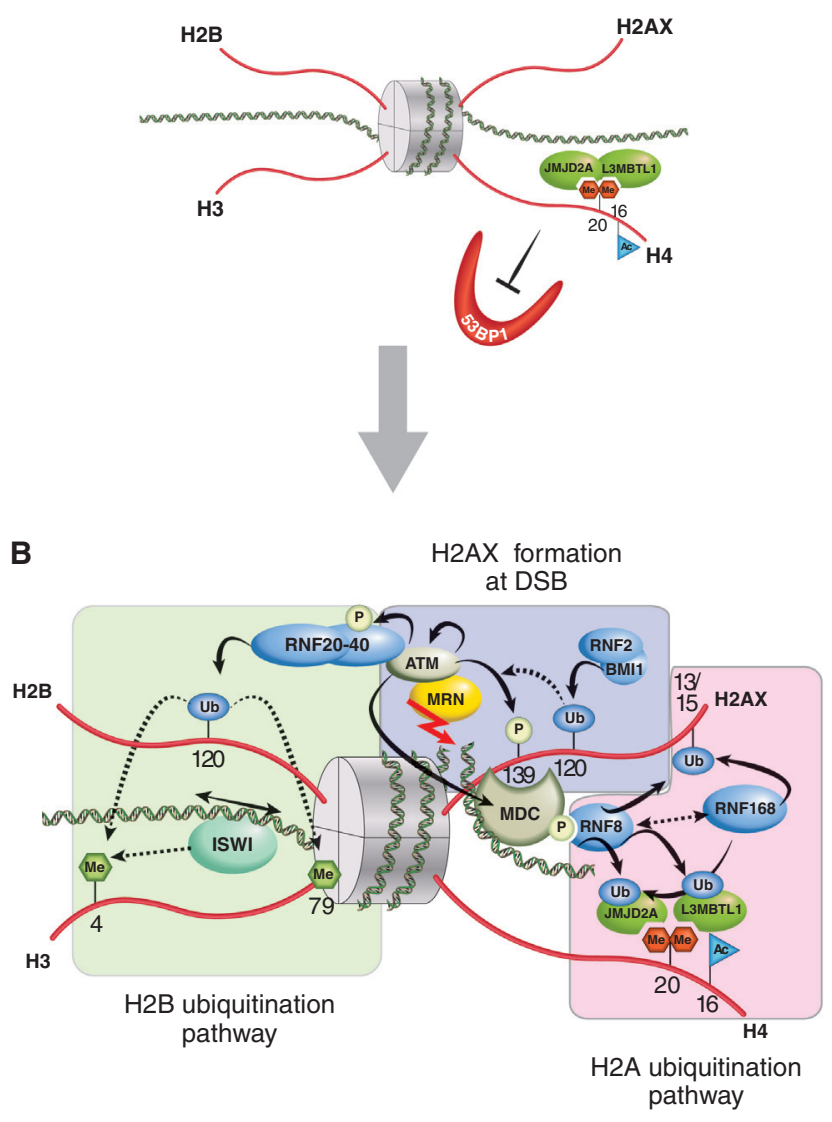

Initiation of DNA damage repair

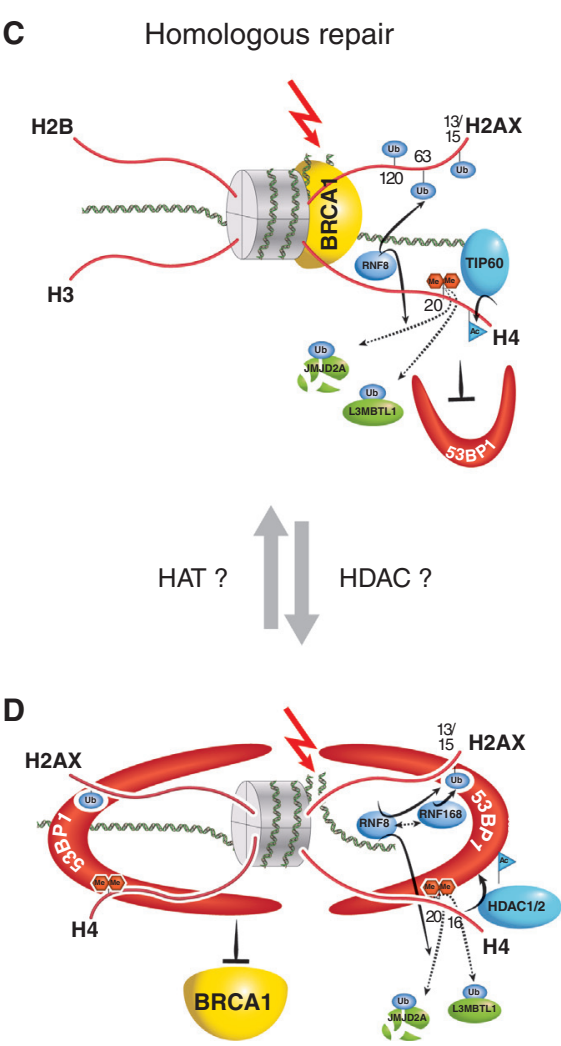

Nonhomologous end joining

Figure 4. Role of histone PTMs in DNA damage repair. (A) Before DNA damage, L3MBTL1 and JMJD2A (possibly also JMJD2B) bind, via their Tudor domains, to H4K20me2 (red hexagons), hindering access by DNA repair proteins, such as 53BP1. (B) When double-strand DNA breaks occur (red arrow), the DNA damage-sensing proteins, such as MRN, act to initiate cascades of protein and histone tail PTMs (blue-shaded area). In particular, the phosphorylation of $\mathrm{H} 2 \mathrm{~A}$ at $\mathrm{S} 139$ represents the conversion of H2A into H2A.X. Subsequent chromatin-remodeling events occur as a consequence of $\mathrm{H} 2 \mathrm{~B}$ ubiquitination (green-shaded area), whereas further ubiquitination events on H2A.X alter local chromatin structure (pink-shaded area). This latter RNF8/RNF168-catalyzed H2A ubiquitination pathway also polyubiquitinates JMJD2A/B for degradation, whereas L3MBTL1 is removed by RNF8mediated ubiquitination. This then allows DSBs in DNA to be repaired by homologous recombinant repair (HRR), where joining occurs between two similar or identical strands of DNA $(C)$; or by nonhomologous end joining (NHEJ), in which the two DNA ends are joined directly, usually with no sequence homology, although, in some cases, regions of microhomology are used $(D)$. (C) During HRR, TIP60 acetylates H4K16, RNF8 ubiquitinates $\mathrm{H} 2 \mathrm{AK} 63$, and selectively allows for BRCA1 binding but not 53BP1. (D) If NHEJ is required, H4K16 is deacetylated (presumably by HDAC1,2) and H2AK15 is ubiquitinated. 53BP1 binds to both H4K20me2 and H2AK15ub, whereas BRCA1 is excluded. To illustrate 53BP1 oligmer formation, only histone H4 and H2AX tails are illustrated in this panel. 
et al. 2004; Endoh et al. 2008; Trojer et al. 2011). BMI-1 functions as an oncogene in medulloblastoma and other malignancies, although its deregulation seems to mostly impact its function as a stem-cell factor (see Grossniklaus and Paro 2014). Given BMI-1's dual role, it is hard to separate its role when considering using it as a drug target, as both functions must be taken into consideration. RING1B has been proposed to control the balance between early myeloid progenitors and mature myeloid populations (Cales et al. 2008); potential dysfunction could lead to myeloid dysfunction and/or malignancies. Indeed, RING1B deficiency was found to result in an accelerated onset of hematopoietic neoplasia in the absence of the tumor suppressor, Ink4a (Cales et al. 2008).

Monoubiquitination of $\mathrm{H} 2 \mathrm{~B}$ at Lys120 is also induced at sites of DNA damage and required for DNA DSB repair (reviewed in Prinder et al. 2013). The ubiquitin ligase, RNF20 (really interesting new gene [RING]-finger), when phosphorylated by ATM, likely mediates H2B ubiquitination. Ubiquitination of histone $\mathrm{H} 2 \mathrm{~B}$, in turn, promotes methylation of $\mathrm{H} 3 \mathrm{~K} 4$ and $\mathrm{H} 3 \mathrm{~K} 79$, which is critical for remodeling chromatin to allow access to the DNA repair machinery. The remodeling is partly facilitated by the SNF2h subunit of the ISWI complex, likely through interaction with methylated H3K4, as SNF2h depletion reduces repair, at least by the homologous repair (HR) pathway (Fig. 4B). This H2B ubiquitination branch of the DNA repair pathway is a necessary part of either NHEJ or HR mechanisms at DSB (Pinder et al. 2013).

The HR pathway involves polyubiquitination of $\mathrm{H} 2 \mathrm{~A}$ or H2AX at Lys63 by the RNF8 and RNF168 ubiquitin ligases at sites of DNA DSBs, acting to recruit DNA repair factors, such as BRCA1 (Doil et al. 2009; Campbell et al. 2012). Repair by NHEJ involves histone lysine PTM cross talk to dictate 53BP1 protein recruitment, which interacts with the nucleosome in an oligovalent trans-histone fashion (Fig. 4D). Focal accumulation of 53BP1 at DSBs depends on the specific interaction of its tandem Tudor domain with dimethylated H4K20 (H4K20me2) and ubiquitinylated H2AK15. Rapid induction of H4K16 deacetylation after DSBs facilitates 53BP1-induced DNA damage signaling and DSB repair (Hsiao and Mizzen 2013). In the absence of DNA damage, TIP60 acetyltransferase-mediated $\mathrm{H} 4 \mathrm{~K} 16$ acetylation inhibits the interaction between 53BP1 and H4K20me2 (Tang et al. 2013). Following the initiation of DSB repair, the acetylation status of histone H4K16, written by TIP60 or removed by HDAC1/2, in fact, may act as a switch between BRCA1 and 53BP1 localization to DSB chromatin by affecting the binding affinity of the 53BP1 Tudor domain for H4K20me2 (Tang et al. 2013). These histone modifications (H4K16ac, H4K20me2) could function to balance 53BP1
DSB chromatin occupancy for NHEJ, versus BRCA1 DSB localization and HRR (Fig. 4).

In summary, DSB repair is a complex process involving many proteins and PTMs. When mutated, many of these factors contribute to cancer: among them are TIP60, BRCA1, and 53BP1, documented to have tumor-suppressor function, thus making these and other epigenetic modifying proteins involved in the DNA repair pathway potential cancer drug targets. Conversely, tumors may be made more susceptible to standard cytotoxic therapies if their DNA damage repair pathways are perturbed by targeted pharmacological agents, such as epigenetic therapies.

\section{DRUG-DISCOVERY CHALLENGES FOR HISTONE-MODIFYING TARGETS}

Two possible modes by which epigenetic drug therapy may be able to halt or even prevent the oncogenic process are (1) repressing oncogenes and/or activating tumor-suppressor genes that are deregulated by epigenetic processes (Baylin and Ohm 2006; Jones and Baylin 2007) and (2) overcoming resistance to chemotherapy. The "epigenetic" drugs that are currently being developed primarily target histone-modifying enzymes, histone readers, or other chromatin-associated proteins.

\subsection{Epigenetics and Drug Resistance}

There is evidence to suggest there is an epigenetic basis for resistance to cancer chemotherapy. Because resistance develops to virtually all forms of cancer therapy, overcoming drug resistance remains the biggest obstacle to improving a positive and durable outcome cancer treatment. Examples of epigenetic alterations being attributed to resistance include the aforementioned KDM5A in Section 2.2.2 and overexpression of EZH2, observed during cisplatin chemotherapy; EZH2 overexpression results in increased gene repression and enhanced cell proliferation (Hu et al. 2010; Crea et al. 2011). Clearly, more research is required to understand how epigenetic alterations mechanistically contribute to drug resistance and how to apply epigenetic drug therapy appropriately to patients, depending on an individual's drug and/or (epi)genomic profile.

\subsection{Approved Epigenetic Drugs}

The earliest clinical entries to epigenetic drugs were actually not developed with a focus on histone-modifying targets, but were discovered to interact with chromatin modifiers and express their biological effects through these targets after the fact. Dimethylsulfoxide and the later agent 


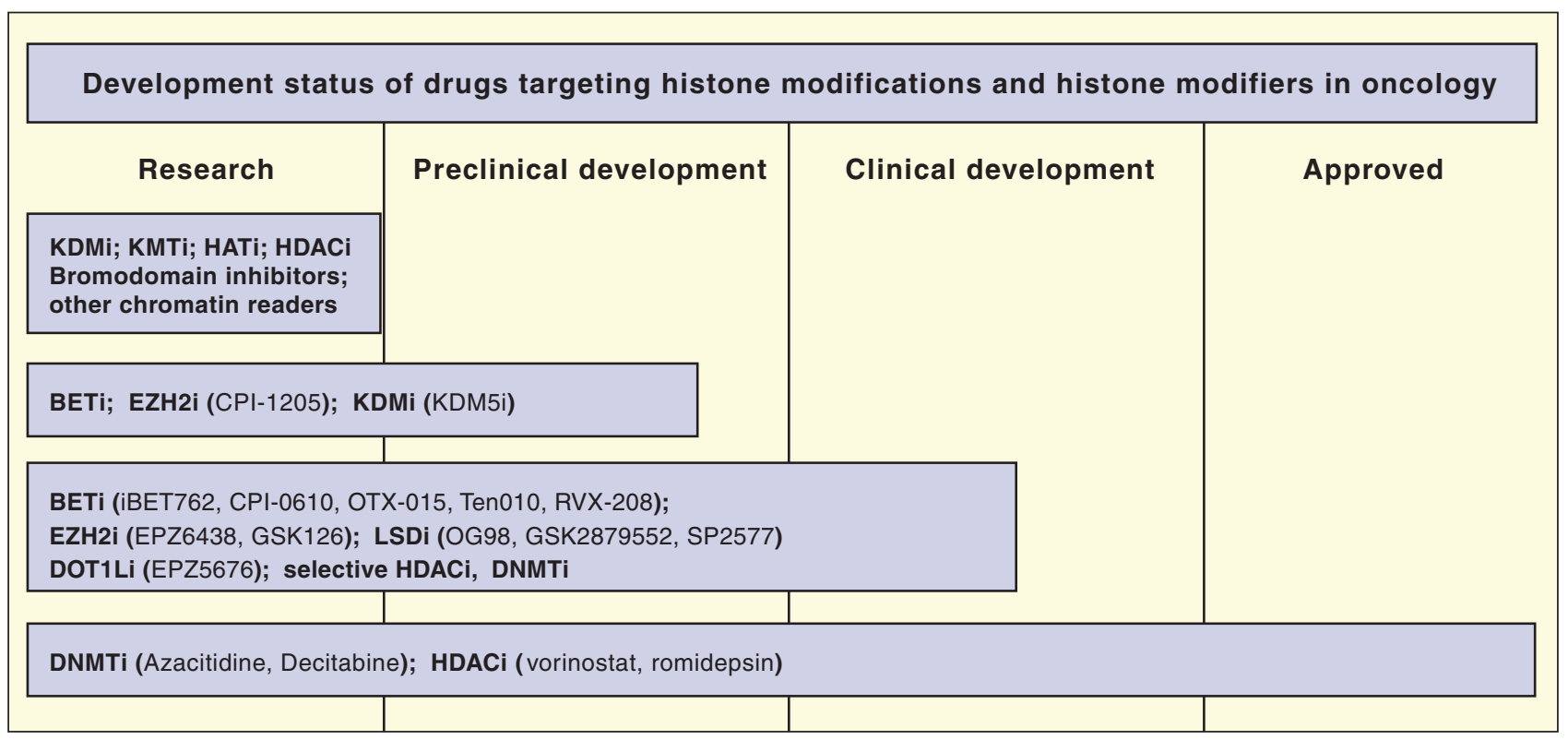

Figure 5. The development status of epigenetic drugs. KDMi, lysine demethylase inhibitor; KMTi, lysine methyltransferase inhibitor; HATi, histone acetyltransferase inhibitor; HDACi, histone deacetylase inhibitor; BETi, bromodomain and extracarboxy terminal domain inhibitor; DNMTi, DNA methyltransferase inhibitor.

HMBA, for example, although explored therapeutically since the 1950s, were only recently shown as inhibitory to a subset of bromodomains (including the BET family).

Among the agents specifically designed against histone-modifying targets that have been clinically approved thus far are the HDAC inhibitors (see Figs. 5 and 6). These drugs (Zolinza, Istodax) broadly inhibit HDACs and show single-agent activity only in a limited set of patients with cutaneous T-cell lymphoma. A large number of clinical trials are now ongoing with these and newer, more subtype-selective HDAC inhibitors (some examples are found in Fig. 8 of Seto and Yoshida 2014) in combination with standard care drugs, in the hopes of expanding the utility of these treatments. Given the early successes with

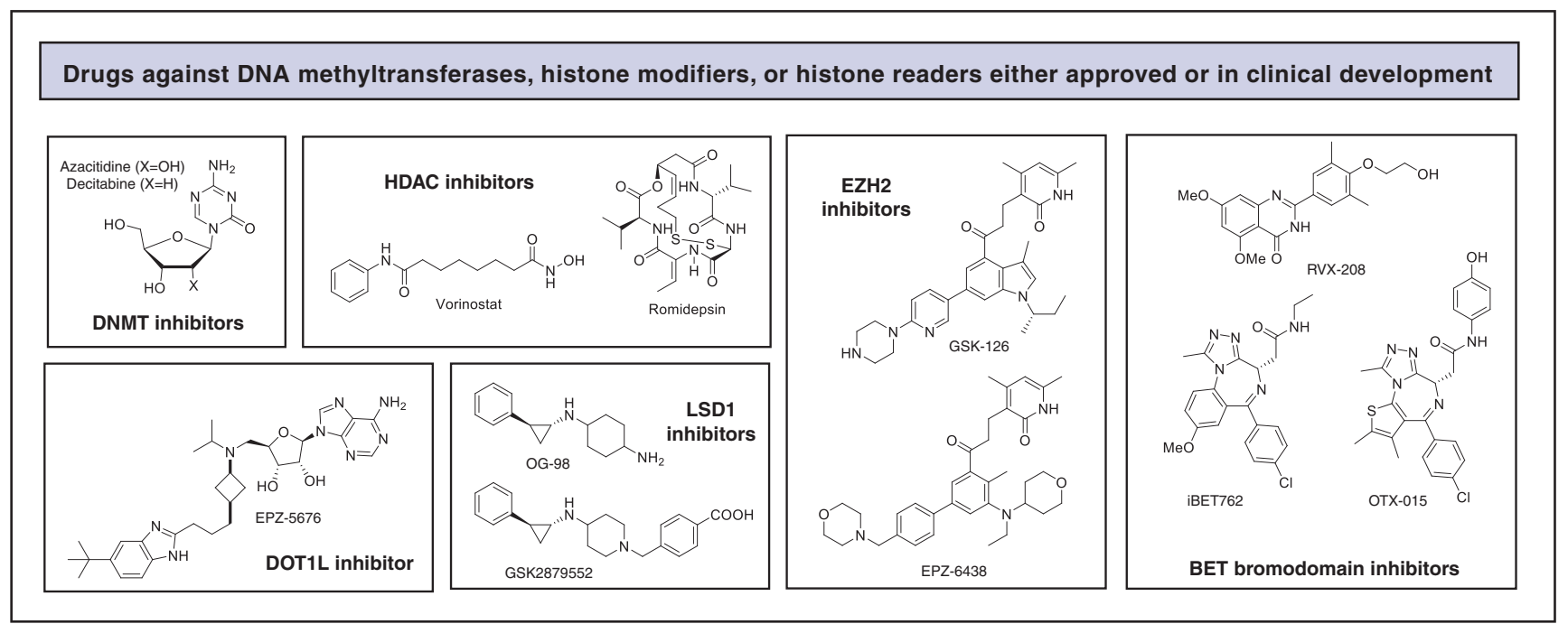

Figure 6. Representative structures of drugs targeting DNA methylation, histone modifications, and histone readers in oncology. 
epigenetic therapy, particularly when used in combination (i.e., HDAC and DNA methylation inhibitors, Vidaza and Dacogen) for the treatment of myelodysplastic syndromes and AML, there has been great interest in producing selective agents that target other histone-modifying proteins.

\subsection{The Epigenetic Drug-Discovery Process}

The enthusiasm for developing novel epigenetic therapeutics has been tempered by the challenges presented in the epigenetic-targeted drug-discovery process (Table 1). Contemporary drug discovery, with some variation, is most commonly seen to consist of three phases: target identification/validation, lead generation, and lead optimization. Optimized lead compounds are then entered into a development pipeline, again consisting of multiple stages. These include the preclinical (or early development) stage, clinical stage (which is typically further subdivided into Phases 1, 2, and 3), and the registration/approval phase. From beginning to end, this discovery/development process can take more than a decade despite myriad efforts on the part of academics, industry, and the regulatory agencies to streamline the process.

Epigenetic drug discovery presents some unique challenges at each stage of discovery and development. For example, in the target identification/validation stage, we still have yet to fully "map" the epigenetic landscape of all cell types, normal or tumorigenic, on a structural, biochemical, and functional level. This fundamental lack of knowledge introduces a number of pragmatic and scientific issues, which must be considered in the drug-discovery process. For example, challenges include identifying the most disease-relevant targets, understanding the associated biology, developing biologically relevant assays with limited tools (e.g., proteins, antibodies, etc.), and finding suitable small molecule activators or inhibitors with few chemical starting points. Cancer relevance for a given target (e.g., a particular KMT like MLL1) is often determined from genomic analyses of patient tumors; this may reveal mutations, translocations, rearrangements, fusions, amplifications, or copy number changes. Additional experimental data is also used to corroborate their role in cancer, such as testing for synthetic lethality or gene silencing. Experimental data using RNA silencing, although beneficial in these analyses, must be interpreted with care, especially for epigenetic enzymes, as knockdown can disrupt protein complexes and not necessarily be directly associated with the catalytic activity. Use of catalytically inactive "dominant-negative" mutants in concert with selective small molecule activators/inhibitors can be more informative. Clinical relevance of a target in oncology, especially in the absence of tool compounds that modify it, may be inferred by correlating a target's expression with mortality, disease-free survival, and/or development of resistance to chemotherapy.

With modern targeted chemotherapies, the ultimate goal is to tailor drugs to patients most likely to respond. Success in this endeavor requires a thorough understanding of the patient, their tumor(s), and the underlying biology driving tumor growth and metastasis. Epigenetic targets, as well as being a good focus for drug development, are increasingly proving to be good biomarkers of cancer etiology and chemotherapy response. This may be determined by tracking various histone mark changes, target gene, and/or downstream gene expression patterns (e.g., looking for overexpression, wild-type expression, mutation, translocation, or partnering as a fusion protein, as illustrated in scenarios of Fig. 2). The presence or absence of a mutated or fusion protein, thus, can provide a binary patient-tailoring marker. For instance, EZH2-activating mutations are observed in subsets of lymphoma, providing a biomarker for this type of lymphoma (Yap et al. 2011; Majer et al. 2012; McCabe et al. 2012), whereas MLL-fusion proteins in rearranged leukemias have altered DOT1L-dependent H3K79 methylation profiles, which is again a biomarker for MLL-rearranged cancers (Bernt and Armstrong 2011). However, aside from EZH2, very few epigenetic activating mutations or translocations have been found in human tumors; many epigenetic gene alterations are predicted to result in loss of function (i.e., loss of tumor-suppressor function, which is extensively discussed in Baylin and Jones 2014), or alteration of function, the latter of which does not constitute a straightforward overexpression consequence. This makes epigenetic targeting and patient tailoring quite challenging - that is, how does one "reactivate" the target when deleted, truncated, or conformationally unfavorable?

Once a compelling target has been identified and selected, a series of assays are constructed to screen compounds and ultimately optimize drug-like properties. An initial high-throughput screening assay is typically biochemical and -analytical in nature, investigating disruption or enhancement of protein-protein interactions and catalytic activity. It is critical that these biochemical assays reflect (or at least, generally, predict) the cellular context of the active process one wishes to modulate. For example, chromatin-modifying proteins can exist in heterogeneous multimeric complexes (e.g., PRC1, PRC2, COMPASS) such that partners and enzymatic substrates may be recruited or exchanged to elicit specific biological responses. It is therefore conceivable that different results may be obtained when screening with various protein forms, such as the apoprotein lacking its nonpolypeptide moiety versus the 
Table 1. Epigenetic drug-discovery challenges

Issues

\section{Target selection}

\section{Chemistry}

\section{Assay development}

In vivo biology

\section{Toxicology}

\section{Clinical}

Few activating mutations, translocations, or synthetic lethal relationships known.

Understanding change-of-function mutations in large multisubunit complexes that represent the most frequent epimutations.

Limited high quality, specific antibodies to epigenetic proteins and histone marks (e.g., confirm target expression, linkage of target to mark).

Biology-driving cancer phenotype unknown or poorly understood.

Roles of PTM of histone versus nonhistone substrates by epigenetic targets unclear.

Existing chemical libraries may not have adequate diversity to provide good starting points.

Few crystal structures solved. Are structures relevant if not reflecting complete complex? Multiple complexes with different functions possible.

Different enzyme/chaperone/substrate combinations may yield different SARs.

Few reference compounds to establish assay signal window, sensitivity, reproducibility.

Assay may not be configured properly to achieve optimal sensitivity (e.g., enzyme in proper complex, with relevant substrate to achieve adequate turnover).

Producing active enzymes difficult, may require coexpression of multimeric complex and specific substrate (nucleosome, histone, nonhistone).

Limited high-quality antibodies to epigenetic proteins and histone marks (quantify mark or target gene product).

Cellular target engagement readout of chromatin adaptors and remodelers.

Histone marks and target genes slow to change, require longer duration studies to assess target engagement (pharmacodynamic [PD] biomarker) and efficacy.

May necessitate higher-compound requirement to conduct studies, earlier optimization of PK properties than traditional paradigm.

May require novel models for tumors with mutations, translocations.

Acute and/or chronic liabilities of specific isoform-targeted epigenetic therapies currently unknown.

Knockout animal data limited; inducible knockouts, dominant negatives preferred, but more scarce, and technically challenging.

Identify and implement appropriate patient selection markers, more challenging if not an activating mutation (overexpression, gene profile?).

Identify and implement suitable PD marker (PTM, target gene, surrogate tissue, or tumor?).

Epigenetic changes at metastatic sites can differ from primary tumor; which should be targeted clinically?

Modified, from Campbell and Tummino 2014, with permission of the American Society for Clinical Investigation. 
complexed form, or using various substrate forms (i.e., peptide vs. protein/histone, core histones, or nucleosomes, as discussed in Sec. 16.2 of Patel 2014). The choice of enzymatic substrates is further complicated by the fact that many epigenetic enzymes can posttranslationally modify nonhistone targets. Among the many known examples are HDAC6, SIRT1, SIRT2, SET7/9, SETD8, SMYD2, PRMT5, and EHMT2/G9a) (Hubbert et al. 2002; Huang et al. 2006; Shi et al. 2007; Pradhan et al. 2009; Karkhanis et al. 2011; Stunkel and Campbell 2011).

The presence of "tool compounds" or chemical probes to understand the translation from biochemical to cellular assays brings us a step closer to the elucidation of in vivo biological function. This collection of specific epigenetic probes is currently quite limited; however, efforts to expand the collection of such tools continue to progress. A tool compound, such as the S-adenosyl methionine (SAM) analog, Sinefungin, for example, can be useful for SAM-dependent enzyme assays on lysine and arginine histone methyltransferase enzymes, but is poorly cell permeable. Other tools that can be used are the recently described selective, cell-active inhibitors of EZH2, DOT1L, SMYD2, G9a/GLP1, PRMT3, JMJD3, LSD1, BET (BRD2-4), L3MBTL1, L3MBTL3, CBP/EP300, PCAF, and BAZ bromodomains (Arrowsmith et al. 2012; Muller and Brown 2012; James et al. 2013; Gallenkamp et al. 2014). It is anticipated that these and future chemical tools will greatly facilitate assay development and our understanding of target biology. However, a cautionary note is warranted: as powerful as probes may be in revealing the mechanistic and phenotypic consequences of inhibiting specific domains of chromatin modifiers and their readers, such data is clearly dependent on the quality of the probes, the thoughtful design of experiments, and the cellular assays designed to monitor their readout, such that the outcome can be most directly linked to the specific target. As more data is generated and more targets are credentialed, probes must continue to be reviewed for specificity and cellular target engagement (i.e., ability to specifically modulate the downstream target-dependent biology, such as a histone mark change) to ensure that the biology observed is properly interpreted.

The challenge of identifying chemical probe molecules of sufficient potency, selectivity, and cell-permeability suggests that traditional chemical libraries may be deficient in the most relevant chemotypes and screening methodologies were not optimal. As such, new chemical diversity is being explored, particularly, using small molecular weight fragment approaches, and generating substrate or cofactor analogs, such as SAM- and Lys/Arg-peptide mimetics for use with histone methyltransferase targets. A growing col- lection of crystal structures has been solved to facilitate drug design, some of which are covered in the structural articles of this collection (see Cheng 2014; Marmorstein and Zhou 2014; Patel 2014; Seto and Yoshida 2014). However, still too few structures represent protein complexes or have a small molecule modulator bound, a problem discussed in Section 16.2 of Patel (2014).

Epigenetic-targeted drug discovery is in its infancy, but steadily evolving to overcome the unique challenges of prosecuting its targets. To be successful, ideally, a comprehensive "epigenetics toolbox" must be assembled to test and better understand the dominant biology, relevant histone marks (or nonhistone PTM), structural biology, appropriate in vitro assays, pharmacodynamics of lead drug and target interactions, and patient tailoring biomarkers (perhaps, a major challenge with today's pharma-favoring genetic features to reflect a real epigenetic basis for sensitivity). The possibility of "antitarget" action must also be determined (i.e., action with another target), which might contribute to clinically unmanageable toxicities.

To accelerate the production of epigenetic drug development tools, a new paradigm has emerged whereby private-public partnerships, such as the Structural Genomics Consortium, have joined forces to generate necessary epigenetic chemical probes, assays, antibodies, and X-ray crystal structures. Other large group efforts are performing sequencing (exome and next-generation) of patient tumors and performing synthetic lethal screens in genomically characterized tumor cell lines. This is helping to identify epigenetic target opportunities and determine patient populations sensitive to therapeutic intervention. It is anticipated that substantial progress will be made in the coming years as a result of knowledge sharing between these pooled collaborative efforts. Such progress is occurring at an increasing rate and, as reflected in Figure 5, early stage drugs targeting histone modifications and modifiers are now progressing through to clinical phases of development. Beyond the initial DNA methyltransferase and HDAC drugs already approved, new chemical entities targeting the BET bromodomains have been entered into a number of clinical studies in a variety of cancers by multiple sponsors (Figs. 5 and 6). Similarly, small molecule inhibitors of the histone methyltransferases, DOT1L and EZH2, have advanced to the clinic, as well as inhibitors of the histone demethylase LSD1. Data from these and subsequent studies will be critical for refining our understanding of the role of histone modifications and histone-modifying enzymes (and their readers) in cancer initiation, cancer progression, and, ultimately, translating to new and improved cancer therapies. 


\section{APPENDICES}

Appendix A. HAT mutations in cancer

\begin{tabular}{|c|c|c|c|c|c|c|}
\hline Gene & $\begin{array}{l}\text { Common } \\
\text { name }\end{array}$ & Tumor types & Cell type & Tissue type & Mutation types & Fusion proteins \\
\hline \multicolumn{7}{|c|}{ MYST family } \\
\hline KAT5 & TIP60 & $\begin{array}{l}\text { Colorectal, head and neck, } \\
\text { stomach }\end{array}$ & Somatic & Epithelial & $\begin{array}{l}\text { Missense, frameshift } \\
\text { nonsense }\end{array}$ & \\
\hline KAT7 & HBOI & $\begin{array}{l}\text { Lung, colorectal, breast, prostate, } \\
\text { ovarian, sarcoma }\end{array}$ & Somatic & Epithelial & $\begin{array}{l}\text { Amplification, missense, } \\
\text { splice }\end{array}$ & \\
\hline $\begin{array}{l}\text { KAT6A/ } \\
\text { MYST3 }\end{array}$ & $\mathrm{MOZ}$ & $\begin{array}{l}\text { Colorectal, lung, breast, acute } \\
\text { myelogenous leukemia }\end{array}$ & Somatic & $\begin{array}{l}\text { Epithelial, } \\
\text { leukemia/ } \\
\text { lymphoma }\end{array}$ & $\begin{array}{l}\text { Nonsense, missense } \\
\text { amplification, } \\
\text { deletion, translocation }\end{array}$ & $\begin{array}{l}\text { MOZ-CBP, MOZ- } \\
\text { EP300, MOZ-TIF2, } \\
\text { MOZ-NCOA3, } \\
\text { MOZ-ASXL2 }\end{array}$ \\
\hline $\begin{array}{l}\text { KAT6B/ } \\
\text { MYST4 }\end{array}$ & MORF & $\begin{array}{l}\text { Colorectal, glioblastoma, lung, } \\
\text { ovarian, acute myelogenous } \\
\text { leukemia }\end{array}$ & Somatic & $\begin{array}{l}\text { Epithelial, } \\
\text { leukemia/ } \\
\text { lymphoma }\end{array}$ & $\begin{array}{l}\text { Nonsense, missense } \\
\text { amplification, deletion } \\
\text { translocation }\end{array}$ & MORF-CBP \\
\hline MYST1 & MOF & $\begin{array}{l}\text { Lung, colorectal, } \\
\text { medulloblastoma }\end{array}$ & Somatic & Epithelial & $\begin{array}{l}\text { Missense, nonsense, } \\
\text { deletion }\end{array}$ & \\
\hline \multicolumn{7}{|c|}{ GNAT family } \\
\hline KAT2A & GCN5 & $\begin{array}{l}\text { Breast, colorectal, prostate, lung, } \\
\text { kidney, sarcoma }\end{array}$ & Somatic & Epithelial & Deletion, amplification & \\
\hline КАТ2B & PCAF & Lung, kidney, sarcoma, colorectal & Somatic & Epithelial & $\begin{array}{l}\text { Missense, frameshift, } \\
\text { deletion, amplification }\end{array}$ & \\
\hline \multicolumn{7}{|c|}{ Orphan family } \\
\hline EP300 & p300 & $\begin{array}{l}\text { Colorectal, breast, pancreatic, } \\
\text { AML, ALL, DLBCL (10\%), } \\
\text { NHL (7\%), FL }(8.7 \%)\end{array}$ & Somatic & $\begin{array}{l}\text { Epithelial, } \\
\text { leukemia } \\
\text { lymphoma }\end{array}$ & $\begin{array}{l}\text { Translocation, nonsense, } \\
\text { frameshift, missense, } \\
\text { other }\end{array}$ & p300-MOZ, MLL-p300 \\
\hline CREBBP & CBP & $\begin{array}{l}\text { ALL }(18.3 \%), \text { AML, DLBCL } \\
\quad(29 \%), \text { NHL }(21 \%)\end{array}$ & Somatic & $\begin{array}{l}\text { Leukemia } \\
\text { lymphoma }\end{array}$ & $\begin{array}{l}\text { Translocation, non-sense, } \\
\text { frameshift, missense, } \\
\text { other }\end{array}$ & $\begin{array}{l}\text { CBP-MOZ, CBP- } \\
\text { MORF, MLL-CBP }\end{array}$ \\
\hline CREBBP & $\mathrm{CBP}$ & $\begin{array}{l}\text { Hematological (Rubstein- Taybe } \\
\text { syndrome) }\end{array}$ & Germline & $\begin{array}{l}\text { Leukemia/ } \\
\text { lymphoma }\end{array}$ & Deletion & \\
\hline $\begin{array}{l}\text { NCOAI/ } \\
\text { KATI3A }\end{array}$ & SRCI & Lung, colorectal & Somatic & Epithelial & Missense, deletion & PAX3-NCOAI \\
\hline $\begin{array}{l}\text { NCOA3/ } \\
\text { KATI3B }\end{array}$ & $\begin{array}{l}\text { CRC-3/ } \\
\text { ACTR }\end{array}$ & Colorectal, ovarian, lung & Somatic & Epithelial & $\begin{array}{l}\text { Nonsense, missense, } \\
\text { amplification, in frame } \\
\text { insertion }\end{array}$ & NCOA3-MOZ \\
\hline KATI3D & CLOCK & Colorectal, glioblastoma, lung & Somatic & Epithelial & $\begin{array}{l}\text { Missense, nonsense, } \\
\text { amplification, other }\end{array}$ & \\
\hline KAT4 & TAFI & $\begin{array}{l}\text { Lung, colorectal, breast, } \\
\text { glioblastoma, ovarian, kidney }\end{array}$ & Somatic & Epithelial & $\begin{array}{l}\text { Missense, nonsense, } \\
\text { splice }\end{array}$ & \\
\hline
\end{tabular}

Adapted from Di Cerbo and Schneider 2013, by permission of Oxford University Press.

NHL, B-cell non-Hodgkin lymphoma; AML, acute myelogenous leukemia; ALL, acute lymphocytic leukemia; DLBCL, diffuse large B-cell lymphoma. 
J.E. Audia and R.M. Campbell

Appendix B. Histone deacetylases in cancer

\begin{tabular}{|c|c|c|c|}
\hline Name & $\begin{array}{l}\text { HDAC } \\
\text { class }\end{array}$ & Substrate(s) & Links to cancer \\
\hline
\end{tabular}

HDAC1 I H4K16, H3K56

Overexpressed in ALL, CLL, Hodgkin's lymphoma, renal cell cancer, breast, gastric, pancreatic, and colorectal (associated with poor prognosis), prostate (high grade, hormoneresistant), lung, and hepatocellular carcinoma (advanced stage)

HDAC2 I $\quad$ H4K16, H3K56

Overexpressed in ALL, Hodgkin's lymphoma, renal cell cancer, lung, colorectal (higher in polyps), cervical, gastric, and prostate (associated with advanced stage and/or poor prognosis); HDAC2-inactivating mutation in $\mathrm{MSI}^{+}$colon, gastric, and endometrial tumors

HDAC3 I I3K9,K14 H4K5 H4K12

Overexpression in CLL, Hodgkin's lymphoma, renal cell cancer, gastric, colorectal, prostate correlated with poor prognosis (coincident with HDAC1, -2 overexpression); higher expression correlated with poor 5-year event-free survival

HDAC8 I ERR $\alpha$,

HDAC4 IIA Not defined

HDAC5 IIA p53 (Sen et al. 2013)

HDAC7 IIA Not defined

HDAC9 IIA Not defined

HDAC6 IIB $\alpha$-tubulin, HSP90, cortactin

HDAC10 IIB Not defined

HDAC11 IV Not defined

SIRT1 III H4K16, H3K9, p53, p73, PTEN, FOX01, FOX03a, FOX04, NICD, MEF2, HIF- $1 \alpha$, HIF- $2 \alpha$, TAF(I)68, SREBP-1c, $\beta$-catenin, RelA/p65, PGC1 $\alpha$, BMAL1, Per2, Ku70, XPA, SMAD7, cortactin, IRS-2, APE1, PCAF, TIP60, p300, SUV39H1, AceCS1, PPAR $\gamma$, ER- $\alpha$, ERR $\alpha$, AR, LXR

Overexpressed in ALL, pediatric neuroblastoma (associated with advanced stage disease; poor survival)

High expression in breast cancer (relative to renal, bladder, and colorectal tumors); associated with prednisone-poor response in ALL

High expression in colorectal cancer (relative to bladder, renal, breast cancer) and medulloblastoma (associated with poor overall survival); underexpressed in AML blasts

High expression in CLL, colorectal (relative to bladder, renal, breast cancer), pancreatic cancer, and childhood ALL (associated with poor survival)

Lower expression in higher grade astrocytoma and glioblastoma (vs. lower grade astrocytoma and normal brain), lung tumors (vs. nontumor epithelial cells, although no correlation with disease-free survival) (Okudela et al. 2013), higher expression observed in medulloblastoma, CLL, Philadephia-negative chronic myeloproliferative neoplasms, and childhood ALL associated with poorer overall survival

Overexpressed in CLL, oral squamous cell cancer (higher in advanced stage), breast cancer (but correlated with better survival; sensitivity to endocrine treatment), DLBCL and AML; expression progressively increased with progression of Philadephia-negative chronic myeloproliferative neoplasms

Reduced expression linked to poor prognosis in lung cancer; overexpressed in CLL; low expression correlated to better survival in advanced stage primary neuroblastoma (Oehme et al. 2013)

Overexpressed in mixed lobular and ductal breast carcinoma (vs. normal breast tissue) (Deubzer et al. 2013); elevated in Mantle cell lymphoma (Shah et al. 2012) and Philadephia-negative chronic myeloproliferative neoplasms

Overexpressed in AML, CLL, colon carcinoma, prostate, ovarian, gastric, melanoma, and a subset of HCC (Chen et al. 2012a); underexpressed in bladder, colon, glioma, prostate (?), ovarian tumors (?) 
Appendix B. Continued

\begin{tabular}{|c|c|c|c|}
\hline Name & $\begin{array}{l}\text { HDAC } \\
\text { class }\end{array}$ & Substrate(s) & Links to cancer \\
\hline SIRT2 & III & $\begin{array}{l}\text { H4K16, H3K56, } \alpha \text {-tubulin, ATP-citrate lyase (Lin } \\
\text { et al. 2013), SETD8 (Serrano et al. 2013), CDK9 } \\
\text { (Zhang et al. 2013) }\end{array}$ & $\begin{array}{l}\text { Higher nuclear expression in GBM (vs. astrocytoma or normal } \\
\text { by IHC) (Imaoka et al. 2012) and grade } 3 \mathrm{ER}^{+} \text {breast cancer } \\
\text { (associated with reduced disease-free survival and increased } \\
\text { frequency of relapse, although the reverse trend was observed } \\
\text { in Grade } 2 \text { tumors) (McGlynn et al. 2014); however, decreased } \\
\text { expression of total SIRT2 in NSCLC (Li et al. 2013b), breast, } \\
\text { GBM, HCC as compared with normal tissue (Park et al. 2012) }\end{array}$ \\
\hline SIRT3 & III & $\begin{array}{l}\text { H4K16, H3K56, H3K9, GDH, IDH2, HMGCS2, } \\
\text { SOD2, AceCS2, Ku70, LCAD, SdhA, PDHA1, and } \\
\text { PDP (Fan et al. 2014) }\end{array}$ & $\begin{array}{l}\text { Overexpressed in CLL (Van Damme et al. 2012); higher levels } \\
\text { associated with node-positive breast cancer }\end{array}$ \\
\hline SIRT4 & III & GDH (ADP-ribosylation) & Underexpressed in AML blasts \\
\hline SIRT5 & III & $\begin{array}{l}\text { Cytochrome c, CPS1 HMGCS2, and SOD1 } \\
\text { (desuccinylation) (Rardin et al. 2013) }\end{array}$ & $\begin{array}{l}\text { SIRT5 suggested to desuccinylate and activate SOD1, inhibiting } \\
\text { lung tumor growth in vitro (Lin et al. 2013) }\end{array}$ \\
\hline SIRT6 & III & H3К9, Н3К56 & Overexpressed in CLL (Van Damme et al. 2012) \\
\hline SIRT7 & III & H3К18, p53 & $\begin{array}{l}\text { Low levels of } \mathrm{H} 3 \mathrm{~K} 18 \mathrm{ac} \text { predict higher risk of prostate cancer, } \\
\text { poor prognosis in pancreatic adenocarcinoma; overexpressed } \\
\text { in CLL (Van Damme et al. 2012) and hepatoceullar cancer; } \\
\text { higher levels associated with node-positive breast cancer }\end{array}$ \\
\hline
\end{tabular}

Adapted from Witt et al. 2009; Bosch-Presegue and Vaquero 2011; Stunkel and Campbell 2011; Barneda-Zahonero and Parra 2012; Houtkooper et al. 2012; Bernt 2013; Gong and Miller 2013; Paredes et al. 2014.

HDAC, histone deacetylase; ALL, acute lymphoblastic leukemia; CLL, chronic lymphocytic leukemia; AML, acute myelogenous leukemia; HCC, hepatocellular carcinoma; ER- $\alpha$, estrogen receptor $\alpha$; GBM, glioblastoma multiforme; GDH, glutamate dehydrogenase; IHC, immunohistochemistry; NSCLC, non-small-cell lung carcinoma.

Appendix C. Selected histone methyltransferases in cancer

\begin{tabular}{|c|c|c|c|}
\hline Name & Synonyms & $\begin{array}{l}\text { Histone } \\
\text { target(s) }\end{array}$ & Links to cancer \\
\hline KMT1A & SUV39H1 & H3К9 & Overexpressed in colorectal cancer (Kang et al. 2007), associated with transcriptional repression \\
\hline KMT1C & G9a, EHMT2 & H3К9 & $\begin{array}{l}\text { Overexpressed in lung cancers (Watanabe et al. 2008; Chen et al. 2010, for advanced lung } \\
\text { cancer), regulation of centrosome duplication via chromatin structure (Kondo et al. 2008) }\end{array}$ \\
\hline KMT1F & SETDB2 & H3К9 & Involved in chromosome segregation (Falandry et al. 2010) \\
\hline KMT2A & MLL & $\mathrm{H} 3 \mathrm{~K} 4$ & Rearranged and translocated in leukemias (Zhang et al. 2012a) \\
\hline KMT2B & MLL2 & $\mathrm{H} 3 \mathrm{~K} 4$ & $\begin{array}{l}\text { Frequently mutated in non-Hodgkin lymphoma (Morin et al. 2011), critical role in } \\
\text { lymphomagenesis (Chung et al. 2012), role in multiple myeloma and Kabuki syndrome }\end{array}$ \\
\hline KMT2C & MLL3 & $\mathrm{H} 3 \mathrm{~K} 4$ & $\begin{array}{l}\text { Germline mutation in colorectal cancer and AML ( } \mathrm{Li} \text { et al. 2013a); mutations in glioblastoma, } \\
\text { melanoma, pancreatic carcinoma, and colorectal cancer }\end{array}$ \\
\hline KMT2D & MLL4 & $\mathrm{H} 3 \mathrm{~K} 4$ & Regulates cell-cycle progression and viability in colon cancer (Ansari et al. 2012) \\
\hline KMT2E & MLL5 & $\mathrm{H} 3 \mathrm{~K} 4$ & $\begin{array}{l}\text { Implicated as a tumor suppressor, MLL5 expression positive prognostic in AML (Damm et al. } \\
\text { 2011) }\end{array}$ \\
\hline KMT3A & SETD2 & H3К36 & $\begin{array}{l}\text { Mutations in high-grade gliomas (Fontebasso et al. 2013), tumor suppressor in breast cancer } \\
\text { and renal cell carcinoma (Hakimi et al. 2012) }\end{array}$ \\
\hline KMT3B & NSD1 & H3K36 & $\begin{array}{l}\text { Mutated in AML, myeloma, and lung cancers, NUP98-NSD1 translocation linked to } \\
\text { tumorogenesis in AML (Wang et al. 2007) }\end{array}$ \\
\hline KMT3C & SMYD2 & H3K36 & $\begin{array}{l}\text { Overexpression in esophageal squamous cell carcinoma correlated with poor survival (Komatsu } \\
\text { et al. 2009) }\end{array}$ \\
\hline KMT3E & SMYD3 & H3K4, H4K5 & Overexpressed in liver, breast, and rectal carcinomas (Van Aller et al. 2012) \\
\hline KMT3F & $\begin{array}{l}\text { WHSC1L1/ } \\
\text { NSD3 }\end{array}$ & H3K36 & $\begin{array}{l}\text { Overexpressed in CML, bladder, lung, and liver cancers (Kang et al. 2013); amplified in human } \\
\text { breast cancer cell lines (Angrand et al. 2001) }\end{array}$ \\
\hline KMT3G & WHSC1/NSD2 & H3К36 & $\begin{array}{l}\text { Implicated in constitutive NF- } \mathrm{kB} \text { signaling for cancer cell proliferation, survival, and tumor } \\
\text { growth (Yang et al. 2012), overexpressed in myeloma because of } \mathrm{t}(4 ; 14) \text { chromosomal } \\
\text { translocation, modulates cMYC in myeloma (Min et al. 2012) }\end{array}$ \\
\hline
\end{tabular}


J.E. Audia and R.M. Campbell

Appendix C. Continued

\begin{tabular}{|c|c|c|c|}
\hline Name & Synonyms & $\begin{array}{l}\text { Histone } \\
\text { target(s) }\end{array}$ & Links to cancer \\
\hline KMT4 & DOT1L & H3К79 & Implicated in MLL-rearranged leukemias (Krivtsov et al. 2008; Bernt and Armstrong 2011) \\
\hline KMT5A & $\begin{array}{l}\text { SETD8/PR- } \\
\text { SET7 }\end{array}$ & $\mathrm{H} 4 \mathrm{~K} 20$ & $\begin{array}{l}\text { Overexpressed in bladder cancer, NSCLC, small cell lung cancer, pancreatic cancer, } \\
\text { hepatocellular carcinoma, and chronic myelogenous leukemia (Takawa et al. 2012) }\end{array}$ \\
\hline KMT6 & $\mathrm{EZH} 2$ & H3К 27 & $\begin{array}{l}\text { Catalytic component of PRC2 complex (Kuzmichev et al. 2002), overexpressed, is a marker for } \\
\text { advanced and metastatic breast and prostate cancer (Chase and Cross 2011), essential for } \\
\text { glioblastoma cancer stem-cell maintenance (Suva et al. 2009), somatic mutations in follicular } \\
\text { and diffuse large B-cell lymphomas (Morin et al. 2010) }\end{array}$ \\
\hline KMT7 & $\begin{array}{l}\text { SET7/SET9/ } \\
\text { SETD7 }\end{array}$ & $\mathrm{H} 3 \mathrm{~K} 4$ & Regulation of the estrogen receptor (Subramanian et al. 2008) \\
\hline PRDM14 & & Unknown & $\begin{array}{l}\text { Amplified and overexpressed in breast cancer (Nishikawa et al. 2007; Moelans et al. 2010), } \\
\text { overexpressed in lymphoid neoplasms, and implicated in initiation of lymphoblastic } \\
\text { leukemia (Dettman et al. 2011) }\end{array}$ \\
\hline PRMT4 & CARM1 & $\begin{array}{l}\text { H3R17, } \\
\text { H3R26 }\end{array}$ & $\begin{array}{l}\text { Deregulated in melanoma (Limm et al. 2013), methylation CBP/P300 required for estrogen- } \\
\text { induced targeting to chromatin (Ceschin et al. 2011) }\end{array}$ \\
\hline PRMT5 & & H4R3, H3R8 & $\begin{array}{l}\text { Essential component of HIF-1 signaling (Lim et al. 2012); silences the tumor suppressor ST7 and } \\
\text { is overexpressed in GBM (Yan et al. 2014), non-Hodgkin's lymphoma (Chung et al. 2013), and } \\
\text { melanoma (Nicholas et al. 2013) }\end{array}$ \\
\hline PRMT6 & H3R2, H3R42 & & $\begin{array}{l}\text { Overexpressed in prostate carcinoma (Vieira et al. 2014); PRMT6 silencing reduces PELP1- } \\
\text { mediated ER activation, proliferation, and colony formation in breast tumor cells (Mann et al. } \\
\text { 2014) }\end{array}$ \\
\hline
\end{tabular}

AML, acute myelogenous leukemia; CML, chronic myelogenous leukemia; MLL, mixed lineage leukemia;

NSCLC, non-small-cell lung carcinoma; PRC2, Polycomb repressive complex 2; HIF-1, hypoxia-inducible factor 1; GBM, glioblastoma multiforme; ER, estrogen receptor.

Appendix D. Histone demethylases in cancer

\begin{tabular}{|c|c|c|c|}
\hline Name & Synonyms & Targets & Links to cancer \\
\hline KDM1A & LSD1, AOF2 & $\begin{array}{l}\mathrm{H} 3 \mathrm{~K} 4 \mathrm{me} 2 / \mathrm{me} 1, \mathrm{H} 3 \mathrm{~K} 9 \mathrm{me} 2 / \\
\text { me1 }\end{array}$ & $\begin{array}{l}\text { Overexpressed in prostate carcinoma, bladder cancer (Kauffman et al. } \\
\text { 2011), ER-negative breast cancer (Lim et al. 2010), neuroblastoma } \\
\text { (Schulte et al. 2009); inhibition in animal models of engrafted AML } \\
\text { (Schenk et al. 2012) }\end{array}$ \\
\hline KDM1B & LSD2, AOF1 & $\mathrm{H} 3 \mathrm{~K} 4 \mathrm{me} 2 / \mathrm{me} 1$ & \\
\hline KDM2A & FBXL11A, JHDM1A & $\mathrm{H} 3 \mathrm{~K} 36 \mathrm{me} 2 / \mathrm{me} 1$ & $\begin{array}{l}\text { Overexpressed in NSCLC; KDM2A knockdown inhibits NSCLC tumor } \\
\text { growth in mouse xenografts (Wagner et al. 2013) }\end{array}$ \\
\hline KDM2B & FBXL10B, JHDM1B & H3K36me2/me1, H3K4me3 & Required for initiation and maintenance of AML (He et al. 2011) \\
\hline KDM3A & JMJD1A, JHDM2A & $\mathrm{H} 3 \mathrm{~K} 9 \mathrm{me} 2 / \mathrm{me} 1$ & $\begin{array}{l}\text { High expression correlated with bad prognosis in colorectal cancer } \\
\text { (Uemura et al. 2010), overexpressed in renal cell carcinoma (Guo } \\
\text { et al. 2011) }\end{array}$ \\
\hline KDM3B & JMJD1B, JHDM2B & $\mathrm{H} 3 \mathrm{~K} 9 \mathrm{me} 2 / \mathrm{me} 1$ & \\
\hline KDM4A & JMJD2A, JHDM3A & $\begin{array}{l}\mathrm{H} 3 \mathrm{~K} 9 \mathrm{me} 3 / \mathrm{me} 2 \\
\mathrm{H} 3 \mathrm{~K} 36 \mathrm{me} 3 / \mathrm{me} 2\end{array}$ & $\begin{array}{l}\text { Required for proliferation of breast cancer cells (Lohse et al. 2011), } \\
\text { attenuated expression in bladder cancer (Kauffman et al. 2011), } \\
\text { required for latency and replication of viruses that cause cancer } \\
\text { (Chang et al. 2011) }\end{array}$ \\
\hline KDM4B & JMJD2B & $\begin{array}{l}\mathrm{H} 3 \mathrm{~K} 9 \mathrm{me} 3 / \mathrm{me} 2 \\
\mathrm{H} 3 \mathrm{~K} 36 \mathrm{me} 3 / \mathrm{me} 2\end{array}$ & $\begin{array}{l}\text { Overexpressed in gastric cancer ( } \mathrm{Li} \text { et al. 2011), required for } \\
\text { proliferation and formation of metastasis in breast cancer cells } \\
\text { (Kawazu et al. 2011) }\end{array}$ \\
\hline $\mathrm{KDM} 4 \mathrm{C}$ & JMJD2C, GASC1 & $\begin{array}{l}\mathrm{H} 3 \mathrm{~K} 9 \mathrm{me} 3 / \mathrm{me} 2 \\
\mathrm{H} 3 \mathrm{~K} 36 \mathrm{me} 3 / \mathrm{me} 2\end{array}$ & $\begin{array}{l}\text { Overexpressed in breast cancer (Liu et al. 2009), esophageal cancer } \\
\text { (Yang et al. 2000), MALT lymphoma (Vinatzer et al. 2008), AML } \\
\text { (Hélias et al. 2008), and lung sarcomatoid carcinoma (Italiano et al. } \\
\text { 2006) }\end{array}$ \\
\hline KDM4D & JMJD2D & $\begin{array}{l}\mathrm{H} 3 \mathrm{~K} 9 \mathrm{me} 3 / \mathrm{me} 2 / \mathrm{me} 1 \\
\mathrm{H} 3 \mathrm{~K} 36 \mathrm{me} 3 / \mathrm{me} 2\end{array}$ & $\begin{array}{l}\text { Required for cell proliferation and survival in colon carcinoma cells } \\
\text { (Kim et al. 2012a; Kim et al. 2012b) }\end{array}$ \\
\hline
\end{tabular}

KDM4E JMJD2E

$\mathrm{H} 3 \mathrm{~K} 9 \mathrm{me} 3 / \mathrm{me} 2$ 
Appendix D. Continued

\begin{tabular}{|c|c|c|c|}
\hline Name & Synonyms & Targets & Links to cancer \\
\hline KDM5A & Jarid1A, RBP2 & $\mathrm{H} 3 \mathrm{~K} 4 \mathrm{me} 3 / \mathrm{me} 2$ & Involved in drug resistance (Sharma et al. 2010) \\
\hline KDM5B & Jarid1B, PLU1 & $\mathrm{H} 3 \mathrm{~K} 4 \mathrm{me} 3 / \mathrm{me} 2$ & $\begin{array}{l}\text { Tumor-suppressive function in metastatic melanoma cells (Roesch } \\
\text { et al. 2006, 2008), proproliferative in breast cancer (Mitra et al. 2011), } \\
\text { and overexpressed in prostate cancer }\end{array}$ \\
\hline KDM5C & Jarid1C, SMCX & $\mathrm{H} 3 \mathrm{~K} 4 \mathrm{me} 3 / \mathrm{me} 2$ & $\begin{array}{l}\text { Inactivating mutations found in clear cell renal carcinoma (Dalgliesh } \\
\text { et al. 2010) }\end{array}$ \\
\hline KDM5D & Jarid1D, SMCY & $\mathrm{H} 3 \mathrm{~K} 4 \mathrm{me} 3 / \mathrm{me} 2$ & \\
\hline KDM6A & UTX, MGC141941 & H3K27me3/me2 & Tumor-suppressive function (Tsai et al. 2010) \\
\hline KDM6B & $\begin{array}{l}\text { JMJD3, KIAA0346, PHF8, } \\
\text { KIAA1111, ZNF422 }\end{array}$ & $\begin{array}{l}\mathrm{H} 3 \mathrm{~K} 27 \mathrm{me} 3 / \mathrm{me} 2, \mathrm{H} 3 \mathrm{~K} 9 \mathrm{me} 2 / \\
\text { me1, H4K20me1 }\end{array}$ & Overexpressed in Hodgkin's lymphoma (Anderton et al. 2011) \\
\hline KDM7 & $\begin{array}{l}\text { KIAA1718, JHDM1D } \\
\quad \text { (KDM7A) }\end{array}$ & $\begin{array}{l}\mathrm{H} 3 \mathrm{~K} 9 \mathrm{me} 2 / \mathrm{me} 1, \mathrm{H} 3 \mathrm{~K} 27 \mathrm{me} 2 / \\
\text { me1 }\end{array}$ & $\begin{array}{l}\text { Increased expression of KDM7A suppresses tumor growth in HeLa and } \\
\text { B16 xenograft models (Osawa et al. 2011) }\end{array}$ \\
\hline KDM8 & JMJD5, FLJ13798 & $\mathrm{H} 3 \mathrm{~K} 36 \mathrm{me} 2$ & $\begin{array}{l}\text { Overexpressed in breast tumors; may play a critical role in regulation of } \\
\text { cell cycle by activating the cyclin A1 locus via demethylation of } \\
\text { H3K36me2 (Hsia et al. 2010) }\end{array}$ \\
\hline
\end{tabular}

\footnotetext{
Adapted, with permission, from Hoffmann et al. 2012, (C) Elsevier.

From ER, estrogen receptor; AML, acute myloid leukemia; NSCLC, non-small-cell lung carcinoma; KDM2A, lysine demethylase 2A; MALT, mucosa-associated lymphoid tissue.
}

\section{REFERENCES}

${ }^{*}$ Reference is also in this subject collection.

* Allis CD, Jenuwein T, Reinberg D. 2014. Overview and concepts. Cold Spring Harb Perspect Biol doi: 10.1101/cshperspect.a018739.

Anderton JA, Bose S, Vockerodt M, Vrzalikova K, Wei W, Kuo M, Helin K, Christensen J, Rowe M, Murray PG, et al. 2011. The H3K27me3 demethylase, KDM6B, is induced by Epstein-Barr virus and over-expressed in Hodgkin's Lymphoma. Oncogene 30: 20372043.

Angrand PO, Apiou F, Stewart AF, Dutrillaux B, Losson R, Chambon P. 2001. NSD3, a new SET domain-containing gene, maps to $8 \mathrm{p} 12$ and is amplified in human breast cancer cell lines. Genomics 74: 79-88.

Ansari KI, Kasiri S, Mishra BP, Mandal SS. 2012. Mixed lineage leukaemia-4 regulates cell-cycle progression and cell viability and its depletion suppresses growth of xenografted tumour in vivo. Br J Cancer 107: 315-324.

Arrowsmith CH, Bountra C, Fish PV, Lee K, Schapira M. 2012. Epigenetic protein families: A new frontier for drug discovery. Nat Rev Drug Discov 11: 384-400.

Bannister AJ, Kouzarides T. 2011. Regulation of chromatin by histone modifications. Cell Res 21: 381-395.

Barber MF, Michishita-Kioi E, Xi Y, Tasselli L, Kioi M, Moqtaderi Z, Tennen RI, Paredes S, Young NL, Chen K, et al. 2012. SIRT7 links H3K18 deacetylation to maintenance of oncogenic transformation. Nature 487: 114-118.

Barneda-Zahonero B, Parra M. 2012. Histone deacetylases and cancer. Mol Oncol 6: 579-589.

* Baylin SB, Jones PA. 2014. Epigenetic determinants of cancer. Cold Spring Harb Perspect Biol doi: 10.1101/cshperspect.a019505.

Baylin SB, Ohm JE. 2006. Epigenetic gene silencing in cancer-A mechanism for early oncogenic pathway addiction? Nat Rev Cancer 6: 107116.

Bell EL, Emerling BM, Ricoult SJ, Guarente L. 2011. SirT3 suppresses hypoxia inducible factor $1 \alpha$ and tumor growth by inhibiting mitochondrial ROS production. Oncogene 30: 2986-2996.

Bernt M. 2013. HDAC expression patterns in pediatric ALL. Leuk Res 37: $1191-1192$.

Bernt KM, Armstrong SA. 2011. A role for DOT1L in MLL-rearranged leukemias. Epigenomics 3: 667-670.
Black JC, Van Rechem C, Whetstine JR. 2012. Histone lysine methylation dynamics: Establishment, regulation, and biological impact. Mol Cell 48: 491-507.

Bosch-Presegue L, Vaquero A. 2011. The dual role of sirtuins in cancer. Genes Cancer 2: 648-662.

Boulikas T. 1989. DNA strand breaks alter histone ADP-ribosylation. Proc Natl Acad Sci 86: 3499-3503.

Bracken AP, Pasini D, Capra M, Prosperini E, Colli E, Helin K. 2003. EZH2 is downstream of the pRB-E2F pathway, essential for proliferation and amplified in cancer. EMBO J 22: 5323-5335.

* Busslinger M, Tarakhovsky A. 2014. Epigenetic control of immunity. Cold Spring Harb Perspect Biol 6: a019307.

Cales C, Roman-Trufero M, Pavon L, Serrano I, Melgar T, Endoh M, Perez C, Koseki H, Vidal M. 2008. Inactivation of the polycomb group protein Ring1B unveils an antiproliferative role in hematopoietic cell expansion and cooperation with tumorigenesis associated with Ink4a deletion. Mol Cell Biol 28: 1018-1028.

Campbell RM, Tummino PJ. 2014. Cancer epigenetics drug discovery and development: The challenge of hitting the mark. J Clin Invest 124: 64-69.

Campbell SJ, Edwards RA, Leung CC, Neculai D, Hodge CD, Dhe-Paganon S, Glover JN. 2012. Molecular insights into the function of RING finger (RNF)-containing proteins hRNF8 and hRNF168 in Ubc13/ Mms2-dependent ubiquitylation. J Biol Chem 287: 23900-23910.

Ceschin DG, Walia M, Wenk SS, Duboe C, Gaudon C, Xiao Y, Fauquier L, Sankar M, Vandel L, Gronemeyer H. 2011. Methylation specifies distinct estrogen-induced binding site repertoires of CBP to chromatin. Genes Dev 25: 1132-1146.

Chang X, Han J, Pang L, Zhao Y, Yang Y, Shen Z. 2009. Increased PADI4 expression in blood and tissues of patients with malignant tumors. BMC Cancer 9: 40.

Chang PC, Fitzgerald LD, Hsia DA, Izumiya Y, Wu CY, Hsieh WP, Lin SF, Campbell M, Lam KS, Luciw PA, et al. 2011. Histone demethylase JMJD2A regulates Kaposi's sarcoma-associated herpesvirus replication and is targeted by a viral transcriptional factor. $J$ Virol 85: $3283-3293$.

Chase A, Cross NC. 2011. Aberrations of EZH2 in cancer. Clin Cancer Res 17: 2613-2618.

Chen Y, Sprung R, Tang Y, Ball H, Sangras B, Kim SC, Falck JR, Peng J, Gu W, Zhao Y. 2007. Lysine propionylation and butyrylation are novel 
post-translational modifications in histones. Mol Cell Proteomics 6: $812-819$.

Chen MW, Hua KT, Kao HJ, Chi CC, Wei LH, Johansson G, Shiah SG, Chen PS, Jeng YM, Cheng TY, et al. 2010. H3K9 histone methyltransferase G9a promotes lung cancer invasion and metastasis by silencing the cell adhesion molecule Ep-CAM. Cancer Res 70: 78307840 .

Chen HC, Jeng YM, Yuan RH, Hsu HC, Chen YL. 2012a. SIRT1 promotes tumorigenesis and resistance to chemotherapy in hepatocellular carcinoma and its expression predicts poor prognosis. Ann Surg Oncol 19: 2011-2019.

Chen YF, Luo RZ, Li Y, Cui BK, Song M, Yang AK, Chen WK. 2012b. High expression levels of COX-2 and $\mathrm{P} 300$ are associated with unfavorable survival in laryngeal squamous cell carcinoma. Eur Arch Otorhinolaryngol 270: 1009-1017.

Chen Q, Chen Y, Bian C, Fujiki R, Yu X. 2013. TET2 promotes histone OGlcNAcylation during gene transcription. Nature 493: 561-564.

* Cheng X. 2014. Structural and functional coordination of DNA and histone methylation. Cold Spring Harb Perspect Biol 6: a018747.

Christophorou MA, Castelo-Branco G, Halley-Stott RP, Oliveira CS, Loos R, Radzisheuskaya A, Mowen KA, Bertone P, Silva JC, Zernicka-Goetz M, et al. 2014. Citrullination regulates pluripotency and histone $\mathrm{H} 1$ binding to chromatin. Nature 507: 104-108.

Chung YR, Schatoff E, Abdel-Wahab O. 2012. Epigenetic alterations in hematopoietic malignancies. Int J Hematol 96: 413-427.

Chung J, Karkhanis V, Tae S, Yan F, Smith P, Ayers LW, Agostinelli C, Pileri S, Denis GV, Baiocchi RA, et al. 2013. Protein arginine methyltransferase 5 (PRMT5) inhibition induces lymphoma cell death through reactivation of the retinoblastoma tumor suppressor pathway and polycomb repressor complex 2 (PRC2) silencing. J Biol Chem 288: 35534-35547.

Crea F, Nobili S, Paolicchi E, Perrone G, Napoli C, Landini I, Danesi R, Mini E. 2011. Epigenetics and chemoresistance in colorectal cancer: An opportunity for treatment tailoring and novel therapeutic strategies. Drug Resist Updat 14: 280-296.

Cuthbert GL, Daujat S, Snowden AW, Erdjument-Bromage H, Hagiwara T, Yamada M, Schneider R, Gregory PD, Tempst P, Bannister AJ, et al. 2004. Histone deimination antagonizes arginine methylation. Cell 118: $545-553$.

Dalgliesh GL, Furge K, Greenman C, Chen L, Bignell G, Butler A, Davies H, Edkins S, Hardy C, Latimer C, et al. 2010. Systematic sequencing of renal carcinoma reveals inactivation of histone modifying genes. $\mathrm{Na}$ ture 463: 360-363.

Damm F, Oberacker T, Thol F, Surdziel E, Wagner K, Chaturvedi A, Morgan M, Bomm K, Gohring G, Lubbert M, et al. 2011. Prognostic importance of histone methyltransferase MLL5 expression in acute myeloid leukemia. J Clin Oncol 29: 682-689.

Daujat S, Bauer UM, Shah V, Turner B, Berger S, Kouzarides T. 2002. Crosstalk between CARM1 methylation and CBP acetylation on histone H3. Curr Biol 12: 2090-2097.

Dawson MA, Prinjha RK, Dittmann A, Giotopoulos G, Bantscheff M, Chan WI, Robson SC, Chung CW, Hopf C, Savitski MM, et al. 2011. Inhibition of BET recruitment to chromatin as an effective treatment for MLL-fusion leukaemia. Nature 478: 529-533.

Dell'Aversana C, Lepore I, Altucci L. 2012. HDAC modulation and cell death in the clinic. Exp Cell Res 318: 1229-1244.

Delmore JE, Issa GC, Lemieux ME, Rahl PB, Shi J, Jacobs HM, Kastritis E, Gilpatrick T, Paranal RM, Qi J, et al. 2011. BET bromodomain inhibition as a therapeutic strategy to target c-Myc. Cell 146: 904-917.

de Napoles M, Mermoud JE, Wakao R, Tang YA, Endoh M, Appanah R, Nesterova TB, Silva J, Otte AP, Vidal M, et al. 2004. Polycomb group proteins Ring1A/B link ubiquitylation of histone $\mathrm{H} 2 \mathrm{~A}$ to heritable gene silencing and $\mathrm{X}$ inactivation. Dev Cell 7: 663-676.

Denis H, Deplus R, Putmans P, Yamada M, Metivier R, Fuks F. 2009. Functional connection between deimination and deacetylation of histones. Mol Cell Biol 29: 4982-4993.
Dettman EJ, Simko SJ, Ayanga B, Carofino BL, Margolin JF, Morse HC 3rd, Justice MJ. 2011. Prdm14 initiates lymphoblastic leukemia after expanding a population of cells resembling common lymphoid progenitors. Oncogene 30: 2859-2873.

Deubzer HE, Schier MC, Oehme I, Lodrini M, Haendler B, Sommer A, Witt O. 2013. HDAC11 is a novel drug target in carcinomas. Int J Cancer 132: 2200-2208.

Dhar SS, Lee SH, Kan PY, Voigt P, Ma L, Shi X, Reinberg D, Lee MG. 2012. Trans-tail regulation of MLL4-catalyzed H3K4 methylation by H4R3 symmetric dimethylation is mediated by a tandem PHD of MLL4. Genes Dev 26: 2749-2762.

Di Cerbo V, Schneider R. 2013. Cancers with wrong HATs: The impact of acetylation. Brief Funct Genomics 12: 231-243.

Doil C, Mailand N, Bekker-Jensen S, Menard P, Larsen DH, Pepperkok R, Ellenberg J, Panier S, Durocher D, Bartek J, et al. 2009. RNF168 binds and amplifies ubiquitin conjugates on damaged chromosomes to allow accumulation of repair proteins. Cell 136: 435-446.

Dorrance AM, Liu S, Yuan W, Becknell B, Arnoczky KJ, Guimond M, Strout MP, Feng L, Nakamura T, Yu L, et al. 2006. Mll partial tandem duplication induces aberrant Hox expression in vivo via specific epigenetic alterations. J Clin Invest 116: 2707-2716.

Drost J, Mantovani F, Tocco F, Elkon R, Comel A, Holstege H, Kerkhoven R, Jonkers J, Voorhoeve PM, Agami R, et al. 2010. BRD7 is a candidate tumour suppressor gene required for p53 function. Nat Cell Biol 12: $380-389$.

Endoh M, Endo TA, Endoh T, Fujimura Y, Ohara O, Toyoda T, Otte AP, Okano M, Brockdorff N, Vidal M, et al. 2008. Polycomb group proteins Ring1A/B are functionally linked to the core transcriptional regulatory circuitry to maintain ES cell identity. Development 135: $1513-1524$.

Falandry C, Fourel G, Galy V, Ristriani T, Horard B, Bensimon E, Salles G, Gilson E, Magdinier F. 2010. CLLD8/KMT1F is a lysine methyltransferase that is important for chromosome segregation. J Biol Chem 285: 20234-20241.

Fan J, Shan C, Kang HB, Elf S, Xie J, Tucker M, Gu TL, Aguiar M, Lonning S, Chen H, et al. 2014. Tyr phosphorylation of PDP1 toggles recruitment between ACAT1 and SIRT3 to regulate the pyruvate dehydrogenase complex. Mol Cell 53: 534-548.

Fang J, Chen T, Chadwick B, Li E, Zhang Y. 2004. Ring1b-mediated H2A ubiquitination associates with inactive $\mathrm{X}$ chromosomes and is involved in initiation of X inactivation. J Biol Chem 279: 52812-52815.

Filippakopoulos P, Qi J, Picaud S, Shen Y, Smith WB, Fedorov O, Morse EM, Keates T, Hickman TT, Felletar I, et al. 2010. Selective inhibition of BET bromodomains. Nature 468: 1067-1073.

Finley LW, Carracedo A, Lee J, Souza A, Egia A, Zhang J, Teruya-Feldstein J, Moreira PI, Cardoso SM, Clish CB, et al. 2011. SIRT3 opposes reprogramming of cancer cell metabolism through HIF1 $\alpha$ destabilization. Cancer Cell 19: 416-428.

Fischle W, Tseng BS, Dormann HL, Ueberheide BM, Garcia BA, Shabanowitz J, Hunt DF, Funabiki H, Allis CD. 2005. Regulation of HP1chromatin binding by histone $\mathrm{H} 3$ methylation and phosphorylation. Nature 438: 1116-1122.

Fiskus W, Sharma S, Qi J, Valenta JA, Schaub LJ, Shah B, Peth K, Portier BP, Rodriguez M, Devaraj SG, et al. 2014. Highly active combination of BRD4 antagonist and histone deacetylase inhibitor against human acute myelogenous leukemia cells. Mol Cancer Ther 13: 1142-1154.

Fontebasso AM, Schwartzentruber J, Khuong-Quang DA, Liu XY, Sturm D, Korshunov A, Jones DT, Witt H, Kool M, Albrecht S, et al. 2013. Mutations in SETD2 and genes affecting histone H3K36 methylation target hemispheric high-grade gliomas. Acta Neuropathol 125: 659669.

Fraga MF, Ballestar E, Villar-Garea A, Boix-Chornet M, Espada J, Schotta G, Bonaldi T, Haydon C, Ropero S, Petrie K, et al. 2005. Loss of acetylation at Lys16 and trimethylation at Lys20 of histone $\mathrm{H} 4$ is a common hallmark of human cancer. Nat Genet 37: 391-400.

French CA, Miyoshi I, Aster JC, Kubonishi I, Kroll TG, Dal Cin P, Vargas SO, Perez-Atayde AR, Fletcher JA. 2001. BRD4 Bromodomain gene 
rearrangement in aggressive carcinoma with translocation $\mathrm{t}(15 ; 19)$. Am J Pathol 159: 1987-1992.

French CA, Ramirez CL, Kolmakova J, Hickman TT, Cameron MJ, Thyne ME, Kutok JL, Toretsky JA, Tadavarthy AK, Kees UR, et al. 2008. BRDNUT oncoproteins: A family of closely related nuclear proteins that block epithelial differentiation and maintain the growth of carcinoma cells. Oncogene 27: 2237-2242.

Gallenkamp D, Gelato KA, Haendler B, Weinmann H. 2014. Bromodomains and their pharmacological inhibitors. ChemMedChem 9: 438464.

Garraway LA, Lander ES. 2013. Lessons from the cancer genome. Cell 153: $17-37$.

Gayther SA, Batley SJ, Linger L, Bannister A, Thorpe K, Chin SF, Daigo Y, Russell P, Wilson A, Sowter HM, et al. 2000. Mutations truncating the EP300 acetylase in human cancers. Nat Genet 24: 300-303.

Ginjala V, Nacerddine K, Kulkarni A, Oza J, Hill SJ, Yao M, Citterio E, van Lohuizen M, Ganesan S. 2011. BMI1 is recruited to DNA breaks and contributes to DNA damage-induced H2A ubiquitination and repair. Mol Cell Biol 31: 1972-1982.

Gong F, Miller KM. 2013. Mammalian DNA repair: HATs and HDACs make their mark through histone acetylation. Mutat Res 750: $23-30$.

* Grossniklaus U, Paro R. 2014. Transcriptional silencing by Polycombgroup proteins. Cold Spring Harb Perspect Biol 6: a019331.

Guccione E, Bassi C, Casadio F, Martinato F, Cesaroni M, Schuchlautz H, Luscher B, Amati B. 2007. Methylation of histone H3R2 by PRMT6 and $\mathrm{H} 3 \mathrm{~K} 4$ by an MLL complex are mutually exclusive. Nature 449: 933-937.

Guo X, Shi M, Sun L, Wang Y, Gui Y, Cai Z, Duan X. 2011. The expression of histone demethylase JMJD1A in renal cell carcinoma. Neoplasma 58: $153-157$.

Haigis MC, Sinclair DA. 2010. Mammalian sirtuins: Biological insights and disease relevance. Annu Rev Pathol 5: 253-295.

Haigis MC, Deng CX, Finley LW, Kim HS, Gius D. 2012. SIRT3 is a mitochondrial tumor suppressor: A scientific tale that connects aberrant cellular ROS, the Warburg effect, and carcinogenesis. Cancer Res 72: $2468-2472$.

Hakimi AA, Chen YB, Wren J, Gonen M, Abdel-Wahab O, Heguy A, Liu H, Takeda S, Tickoo SK, Reuter VE, et al. 2012. Clinical and pathologic impact of select chromatin-modulating tumor suppressors in clear cell renal cell carcinoma. Eur Urol 63: 848-854.

Hanahan D, Weinberg RA. 2011. Hallmarks of cancer: The next generation. Cell 144: 646-674.

Hanover JA. 2010. Epigenetics gets sweeter: O-GlcNAc joins the 'histone code'. Chem Biol 17: 1272-1274.

Harris WJ, Huang X, Lynch JT, Spencer GJ, Hitchin JR, Li Y, Ciceri F, Blaser JG, Greystoke BF, Jordan AM, et al. 2012. The histone demethylase KDM1A sustains the oncogenic potential of MLL-AF9 leukemia stem cells. Cancer Cell 21: 473-487.

Harte MT, O’Brien GJ, Ryan NM, Gorski JJ, Savage KI, Crawford NT, Mullan PB, Harkin DP. 2010. BRD7, a subunit of SWI/SNF complexes, binds directly to BRCA1 and regulates BRCA1-dependent transcription. Cancer Res 70: 2538-2547.

He J, Nguyen AT, Zhang Y. 2011. KDM2b/JHDM1b, an H3K36me2specific demethylase, is required for initiation and maintenance of acute myeloid leukemia. Blood 117: 3869-3880.

Hélias C, Struski S, Gervais C, Leymarie V, Mauvieux L, Herbrecht R, Lessard M. 2008. Polycythemia vera transforming to acute myeloid leukemia and complex abnormalities including 9p homogeneously staining region with amplification of MLLT3, JMJD2C, JAK2, and SMARCA2. Cancer Genet Cytogenet 180: 51-55.

Herranz N, Dave N, Millanes-Romero A, Morey L, Diaz VM, LorenzFonfria V, Gutierrez-Gallego R, Jeronimo C, Di Croce L, Garcia de Herreros A, et al. 2012. Lysyl oxidase-like 2 deaminates lysine 4 in histone H3. Mol Cell 46: 369-376.
Hirota T, Lipp JJ, Toh BH, Peters JM. 2005. Histone H3 serine 10 phosphorylation by Aurora B causes HP1 dissociation from heterochromatin. Nature 438: 1176-1180.

Hoffmann I, Roatsch M, Schmitt ML, Carlino L, Pippel M, Sippl W, Jung M. 2012. The role of histone demethylases in cancer therapy. Mol Oncol 6: 683-703.

Hou X, Li Y, Luo RZ, Fu JH, He JH, Zhang LJ, Yang HX. 2012. High expression of the transcriptional co-activator p300 predicts poor survival in resectable non-small cell lung cancers. Eur J Surg Oncol 38: $523-530$.

Houtkooper RH, Pirinen E, Auwerx J. 2012. Sirtuins as regulators of metabolism and healthspan. Nat Rev Mol Cell Biol 13: 225-238.

Hsia DA, Tepper CG, Pochampalli MR, Hsia EY, Izumiya C, Huerta SB, Wright ME, Chen HW, Kung HJ, Izumiya Y. 2010. KDM8, a H3K36me2 histone demethylase that acts in the cyclin Al coding region to regulate cancer cell proliferation. Proc Natl Acad Sci 107: 9671-9676.

Hsiao KY, Mizzen CA. 2013. Histone H4 deacetylation facilitates 53BP1 DNA damage signaling and double-strand break repair. J Mol Cell Biol 5: $157-165$.

Hu S, Yu L, Li Z, Shen Y, Wang J, Cai J, Xiao L, Wang Z. 2010. Overexpression of EZH2 contributes to acquired cisplatin resistance in ovarian cancer cells in vitro and in vivo. Cancer Biol Ther 10: 788-795.

Huang J, Perez-Burgos L, Placek BJ, Sengupta R, Richter M, Dorsey JA, Kubicek S, Opravil S, Jenuwein T, Berger SL. 2006. Repression of p53 activity by Smyd2-mediated methylation. Nature 444: 629-632.

Hubbert C, Guardiola A, Shao R, Kawaguchi Y, Ito A, Nixon A, Yoshida M, Wang XF, Yao TP. 2002. HDAC6 is a microtubule-associated deacetylase. Nature 417: 455-458.

Hyllus D, Stein C, Schnabel K, Schiltz E, Imhof A, Dou Y, Hsieh J, Bauer UM. 2007. PRMT6-mediated methylation of R2 in histone H3 antagonizes H3 K4 trimethylation. Genes Dev 21: 3369-3380.

Imaoka N, Hiratsuka M, Osaki M, Kamitani H, Kambe A, Fukuoka J, Kurimoto M, Nagai S, Okada F, Watanabe T, et al. 2012. Prognostic significance of sirtuin 2 protein nuclear localization in glioma: An immunohistochemical study. Oncol Rep 28: 923-930.

Italiano A, Attias R, Aurias A, Pérot G, Burel-Vandenbos F, Otto J, Venissac N, Pedeutour F. 2006. Molecular cytogenetic characterization of a metastatic lung sarcomatoid carcinoma: 9p23 neocentromere and 9p23 p24 amplification including JAK2 and JMJD2C. Cancer Genet Cytogenet 167: 122-130.

Iyer NG, Ozdag H, Caldas C. 2004. p300/CBP and cancer. Oncogene 23: $4225-4231$.

James LI, Korboukh VK, Krichevsky L, Baughman BM, Herold JM, Norris JL, Jin J, Kireev DB, Janzen WP, Arrowsmith CH, et al. 2013. Small-molecule ligands of methyl-lysine binding proteins: Optimization of selectivity for L3MBTL3. J Med Chem 56: 7358-7371.

Jennings LE, Measures AR, Wilson BG, Conway SJ. 2014. Phenotypic screening and fragment based approaches to the discovery of small molecule bromodomain ligands. Future Med Chem 6: 179-204.

Jenuwein T, Allis CD. 2001. Translating the histone code. Science 293: $1074-1080$.

Jiang T, Zhou X, Taghizadeh K, Dong M, Dedon PC. 2007. N-formylation of lysine in histone proteins as a secondary modification arising from oxidative DNA damage. Proc Natl Acad Sci 104: 60-65.

Jones PA, Baylin SB. 2007. The epigenomics of cancer. Cell 128: 683-692.

Jung KH, Noh JH, Kim JK, Eun JW, Bae HJ, Xie HJ, Chang YG, Kim MG, Park H, Lee JY, et al. 2012. HDAC2 overexpression confers oncogenic potential to human lung cancer cells by deregulating expression of apoptosis and cell cycle proteins. J Cell Biochem 113: 2167-2177.

Kadoch C, Hargreaves DC, Hodges C, Elias L, Ho L, Ranish J, Crabtree GR. 2013. Proteomic and bioinformatic analysis of mammalian SWI/ SNF complexes identifies extensive roles in human malignancy. Nat Genet 45: 592-601.

Kaeser MD, Aslanian A, Dong MQ, Yates JR 3rd, Emerson BM. 2008. BRD7, a novel PBAF-specific SWI/SNF subunit, is required for target 
gene activation and repression in embryonic stem cells. J Biol Chem 283: 32254-32263.

Kang MY, Lee BB, Kim YH, Chang DK, Kyu Park S, Chun HK, Song SY, Park J, Kim DH. 2007. Association of the SUV39H1 histone methyltransferase with the DNA methyltransferase 1 at mRNA expression level in primary colorectal cancer. Int J Cancer 121: 2192-2197.

Kang D, Cho HS, Toyokawa G, Kogure M, Yamane Y, Iwai Y, Hayami S, Tsunoda T, Field HI, Matsuda K, et al. 2013. The histone methyltransferase Wolf-Hirschhorn syndrome candidate 1-like 1 (WHSC1L1) is involved in human carcinogenesis. Genes Chromosomes Cancer 52: $126-139$.

Karkhanis V, Hu YJ, Baiocchi RA, Imbalzano AN, Sif S. 2011. Versatility of PRMT5-induced methylation in growth control and development. Trends Biochem Sci 36: 633-641.

Kauffman EC, Robinson BD, Downes MJ, Powell LG, Lee MM, Scherr DS, Gudas LJ, Mongan NP. 2011. Role of androgen receptor and associated lysine-demethylase coregulators, LSD1 and JMJD2A, in localized and advanced human bladder cancer. Mol Carcinog 50: 931944.

Kawazu M, Saso K, Tong KI, McQuire T, Goto K, Son DO, Wakeham A, Miyagishi M, Mak TW, Okada H. 2011. Histone demethylase JMJD2B functions as a co-factor of estrogen receptor in breast cancer proliferation and mammary gland development. PLoS One 6: e17830.

Khan SN, Jankowska AM, Mahfouz R, Dunbar AJ, Sugimoto Y, Hosono N, Hu Z, Cheriyath V, Vatolin S, Przychodzen B, et al. 2013. Multiple mechanisms deregulate EZH2 and histone $\mathrm{H} 3$ lysine 27 epigenetic changes in myeloid malignancies. Leukemia 27: 1301-1309.

Kim TD, Oh S, Shin S, Janknecht R. 2012a. Regulation of tumor suppressor p53 and HCT116 cell physiology by histone demethylase JMJD2D/KDM4D. PLoS One 7: e34618.

Kim TD, Shin S, Berry WL, Oh S, Janknecht R. 2012b. The JMJD2A demethylase regulates apoptosis and proliferation in colon cancer cells. J Cell Biochem 113: 1368-1376.

Komatsu S, Imoto I, Tsuda H, Kozaki KI, Muramatsu T, Shimada Y, Aiko S, Yoshizumi Y, Ichikawa D, Otsuji E, et al. 2009. Overexpression of SMYD2 relates to tumor cell proliferation and malignant outcome of esophageal squamous cell carcinoma. Carcinogenesis 30: 1139-1146.

Kondo Y, Shen L, Ahmed S, Boumber Y, Sekido Y, Haddad BR, Issa JP. 2008. Downregulation of histone H3 lysine 9 methyltransferase G9a induces centrosome disruption and chromosome instability in cancer cells. PLoS One 3: e2037.

Kouzarides T. 2007. Chromatin modifications and their function. Cell 128: $693-705$.

Krivtsov AV, Armstrong SA. 2007. MLL translocations, histone modifications and leukaemia stem-cell development. Nat Rev Cancer 7: 823833.

Krivtsov AV, Feng Z, Lemieux ME, Faber J, Vempati S, Sinha AU, Xia X, Jesneck J, Bracken AP, Silverman LB, et al. 2008. H3K79 methylation profiles define murine and human MLL-AF4 leukemias. Cancer Cell 14: $355-368$.

Kuzmichev A, Nishioka K, Erdjument-Bromage H, Tempst P, Reinberg D. 2002. Histone methyltransferase activity associated with a human multiprotein complex containing the Enhancer of Zeste protein. Genes Dev 16: 2893-2905.

Lautz TB, Naiditch JA, Clark S, Chu F, Madonna MB. 2012. Efficacy of class I and II vs class III histone deacetylase inhibitors in neuroblastoma. J Pediatr Surg 47: 1267-1271.

Li P, Yao H, Zhang Z, Li M, Luo Y, Thompson PR, Gilmour DS, Wang Y. 2008. Regulation of p53 target gene expression by peptidylarginine deiminase 4. Mol Cell Biol 28: 4745-4758.

Li W, Zhao L, Zang W, Liu Z, Chen L, Liu T, Xu D, Jia J. 2011. Histone demethylase JMJD2B is required for tumor cell proliferation and survival and is overexpressed in gastric cancer. Biochem Biophys Res Commun 416: 372-378.

Li WD, Li QR, Xu SN, Wei FJ, Ye ZJ, Cheng JK, Chen JP. 2013a. Exome sequencing identifies an MLL3 gene germ line mutation in a pedigree of colorectal cancer and acute myeloid leukemia. Blood 121: 14781479.

Li Z, Xie QR, Chen Z, Lu S, Xia W. 2013b. Regulation of SIRT2 levels for human non-small cell lung cancer therapy. Lung Cancer 82: 9-15.

Lim S, Janzer A, Becker A, Zimmer A, Schüle R, Buettner R, Kirfel J. 2010. Lysine-specific demethylase 1 (LSD1) is highly expressed in ER-negative breast cancers and a biomarker predicting aggressive biology. Carcinogenesis 31: 512-520.

Lim JH, Choi YJ, Cho CH, Park JW. 2012. Protein arginine methyltransferase 5 is an essential component of the hypoxia-inducible factor 1 signaling pathway. Biochem Biophys Res Commun 418: 254-259.

Limm K, Ott C, Wallner S, Mueller DW, Oefner P, Hellerbrand C, Bosserhoff AK. 2013. Deregulation of protein methylation in melanoma. Eur J Cancer 49: 1305-1313.

Lin R, Tao R, Gao X, Li T, Zhou X, Guan KL, Xiong Y, Lei QY. 2013. Acetylation stabilizes ATP-citrate lyase to promote lipid biosynthesis and tumor growth. Mol Cell 51: 506-518.

Liu G, Bollig-Fischer A, Kreike B, van de Vijver MJ, Abrams J, Ethier SP, Yang ZQ. 2009. Genomic amplification and oncogenic properties of the GASC1 histone demethylase gene in breast cancer. Oncogene 28: 4491-4500.

Lockwood WW, Zejnullahu K, Bradner JE, Varmus H. 2012. Sensitivity of human lung adenocarcinoma cell lines to targeted inhibition of BET epigenetic signaling proteins. Proc Natl Acad Sci 109: 1940819413.

Lohse B, Nielsen AL, Kristensen JB, Helgstrand C, Cloos PA, Olsen L, Gajhede M, Clausen RP, Kristensen JL. 2011. Targeting histone lysine demethylases by truncating the histone 3 tail to obtain selective substrate-based inhibitors. Angew Chem Int Ed Engl 50: 9100-9103.

Majer CR, Jin L, Scott MP, Knutson SK, Kuntz KW, Keilhack H, Smith JJ, Moyer MP, Richon VM, Copeland RA, et al. 2012. A687V EZH2 is a gain-of-function mutation found in lymphoma patients. FEBS Lett 586: $3448-3451$.

Mann M, Zou Y, Chen Y, Brann D, Vadlamudi R. 2014. PELP1 oncogenic functions involve alternative splicing via PRMT6. Mol Oncol 8: 389400.

* Marmorstein R, Zhou M-M. 2014. Writers and readers of histone acetylation: Structure, mechanism, and inhibition. Cold Spring Harb Perspect Biol 6: a018762.

Martin C, Zhang Y. 2007. Mechanisms of epigenetic inheritance. Curr Opin Cell Biol 19: 266-272.

McBrian MA, Behbahan IS, Ferrari R, Su T, Huang TW, Li K, Hong CS, Christofk HR, Vogelauer M, Seligson DB, et al. 2013. Histone acetylation regulates intracellular $\mathrm{pH}$. Mol Cell 49: 310-321.

McCabe MT, Graves AP, Ganji G, Diaz E, Halsey WS, Jiang Y, Smitheman KN, Ott HM, Pappalardi MB, Allen KE, et al. 2012. Mutation of A677 in histone methyltransferase EZH2 in human B-cell lymphoma promotes hypertrimethylation of histone $\mathrm{H} 3$ on lysine 27 (H3K27). Proc Natl Acad Sci 109: 2989-2994.

McGlynn LM, Zino S, MacDonald AI, Curle J, Reilly JE, Mohammed ZM, McMillan DC, Mallon E, Payne AP, Edwards J, et al. 2014. SIRT2: Tumour suppressor or tumour promoter in operable breast cancer? Eur J Cancer 50: 290-301.

Mercurio C, Minucci S, Pelicci PG. 2010. Histone deacetylases and epigenetic therapies of hematological malignancies. Pharmacol Res 62: $18-34$.

Mertz JA, Conery AR, Bryant BM, Sandy P, Balasubramanian S, Mele DA, Bergeron L, Sims RJ 3rd. 2011. Targeting MYC dependence in cancer by inhibiting BET bromodomains. Proc Natl Acad Sci 108: 1666916674.

Messner S, Altmeyer M, Zhao H, Pozivil A, Roschitzki B, Gehrig P, Rutishauser D, Huang D, Caflisch A, Hottiger MO. 2010. PARP1 ADPribosylates lysine residues of the core histone tails. Nucleic Acids Res 38: $6350-6362$. 
Migliori V, Phalke S, Bezzi M, Guccione E. 2010. Arginine/lysine-meth$\mathrm{yl} /$ methyl switches: Biochemical role of histone arginine methylation in transcriptional regulation. Epigenomics 2: 119-137.

Min DJ, Ezponda T, Kim MK, Will CM, Martinez-Garcia E, Popovic R, Basrur V, Elenitoba-Johnson KS, Licht JD. 2012. MMSET stimulates myeloma cell growth through microRNA-mediated modulation of c-MYC. Leukemia 27: 686-694.

Minucci S, Pelicci PG. 2006. Histone deacetylase inhibitors and the promise of epigenetic (and more) treatments for cancer. Nat Rev Cancer 6: 38-51.

Mitra D, Das PM, Huynh FC, Jones FE. 2011. Jumonji/ARID1 B (JARID1B) protein promotes breast tumor cell cycle progression through epigenetic repression of microRNA let-7e. J Biol Chem 286: 4053140535.

Moelans CB, de Weger RA, Monsuur HN, Vijzelaar R, van Diest PJ. 2010. Molecular profiling of invasive breast cancer by multiplex ligationdependent probe amplification-based copy number analysis of tumor suppressor and oncogenes. Mod Pathol 23: 1029-1039.

Morin RD, Johnson NA, Severson TM, Mungall AJ, An J, Goya R, Paul JE, Boyle M, Woolcock BW, Kuchenbauer F, et al. 2010. Somatic mutations altering EZH2 (Tyr641) in follicular and diffuse large B-cell lymphomas of germinal-center origin. Nat Genet 42: 181-185.

Morin RD, Mendez-Lago M, Mungall AJ, Goya R, Mungall KL, Corbett RD, Johnson NA, Severson TM, Chiu R, Field M, et al. 2011. Frequent mutation of histone-modifying genes in non-Hodgkin lymphoma. Nature 476: 298-303.

Mozzetta C, Pontis J, Fritsch L, Robin P, Portoso M, Proux C, Margueron R, Ait-Si-Ali S. 2014. The histone H3 lysine 9 methyltransferases G9a and GLP regulate polycomb repressive complex 2-mediated gene silencing. Mol Cell 53: 277-289.

Muller S, Brown PJ. 2012. Epigenetic chemical probes. Clin Pharmacol Ther 92: 689-693.

Muraoka M, Konishi M, Kikuchi-Yanoshita R, Tanaka K, Shitara N, Chong JM, Iwama T, Miyaki M. 1996. p300 gene alterations in colorectal and gastric carcinomas. Oncogene 12: 1565-1569.

Nakagawa M, Oda Y, Eguchi T, Aishima S, Yao T, Hosoi F, Basaki Y, Ono M, Kuwano M, Tanaka M, et al. 2007. Expression profile of class I HDACs in human cancer tissues. Oncology Rep 18: 769-774.

Nicholas C, Yang J, Peters SB, Bill MA, Baiocchi RA, Yan F, Sif S, Tae S, Gaudio E, Wu X, et al. 2013. PRMT5 is upregulated in malignant and metastatic melanoma and regulates expression of MITF and p27(Kip1.). PLoS One 8: e74710.

Nishikawa N, Toyota M, Suzuki H, Honma T, Fujikane T, Ohmura T, Nishidate T, Ohe-Toyota M, Maruyama R, Sonoda T, et al. 2007. Gene amplification and overexpression of PRDM14 in breast cancers. Cancer Res 67: 9649-9657.

Oehme I, Linke JP, Bock BC, Milde T, Lodrini M, Hartenstein B, Wiegand I, Eckert C, Roth W, Kool M, et al. 2013. Histone deacetylase 10 promotes autophagy-mediated cell survival. Proc Natl Acad Sci 110: E2592-E2601.

Okudela K, Mitsui H, Suzuki T, Woo T, Tateishi Y, Umeda S, Saito Y, Tajiri M, Masuda M, Ohashi K. 2013. Expression of HDAC9 in lung cancer-Potential role in lung carcinogenesis. Int J Clin Exp Pathol 7: $213-220$

Ong CT, Corces VG. 2011. Enhancer function: New insights into the regulation of tissue-specific gene expression. Nat Rev Genet 12: 283-293.

Osawa T, Muramatsu M, Wang F, Tsuchida R, Kodama T, Minami T, Shibuya M. 2011. Increased expression of histone demethylase JHDM1D under nutrient starvation suppresses tumor growth via down-regulating angiogenesis. Proc Natl Acad Sci 108: 20725-20729.

Pan MR, Peng G, Hung WC, Lin SY. 2011. Monoubiquitination of H2AX protein regulates DNA damage response signaling. J Biol Chem 286: 28599-28607.

Panier S, Durocher D. 2013. Push back to respond better: Regulatory inhibition of the DNA double-strand break response. Nat Rev Mol Cell Biol 14: 661-672.
Paredes S, Villanova L, Chua KF. 2014. Molecular pathways: Emerging roles of mammalian Sirtuin SIRT7 in cancer. Clin Cancer Res 20: $1741-1746$.

Park SH, Zhu Y, Ozden O, Kim HS, Jiang H, Deng CX, Gius D, Vassilopoulos A. 2012. SIRT2 is a tumor suppressor that connects aging, acetylome, cell cycle signaling, and carcinogenesis. Transl Cancer Res 1: $15-21$.

Pasqualucci L, Dominguez-Sola D, Chiarenza A, Fabbri G, Grunn A, Trifonov V, Kasper LH, Lerach S, Tang H, Ma J, et al. 2011. Inactivating mutations of acetyltransferase genes in B-cell lymphoma. Nature 471: $189-195$.

* Patel DJ. 2014. A structural perspective on readout of epigenetic histone and DNA methylation marks. Cold Spring Harb Perspect Biol doi: 10.1101/cshperspect.a018754.

Pinder JB, Attwood KM, Dellaire G. 2013. Reading, writing, and repair: The role of ubiquitin and the ubiquitin-like proteins in DNA damage signaling and repair. Front Genet 4: 45.

* Pirrotta V. 2014. The necessity of chromatin: A view in perspective. Cold Spring Harb Perspect Biol doi: 10.1101/cshperspect.a019547.

Plazas-Mayorca MD, Bloom JS, Zeissler U, Leroy G, Young NL, DiMaggio PA, Krugylak L, Schneider R, Garcia BA. 2010. Quantitative proteomics reveals direct and indirect alterations in the histone code following methyltransferase knockdown. Mol Biosyst 6: 1719-1729.

Pradhan S, Chin HG, Esteve PO, Jacobsen SE. 2009. SET7/9 mediated methylation of non-histone proteins in mammalian cells. Epigenetics 4: $383-387$.

* Qi J. 2014. Bromodomain and extraterminal domain inhibitors (BETi) for cancer therapy: Chemical modulation of chromatin structure. Cold Spring Harb Perspect Biol doi: 10.1101/cshperspect.a018663.

Rardin MJ, He W, Nishida Y, Newman JC, Carrico C, Danielson SR, Guo A, Gut P, Sahu AK, Li B, et al. 2013. SIRT5 regulates the mitochondrial lysine succinylome and metabolic networks. Cell Metab 18: 920-933.

Reichert N, Choukrallah MA, Matthias P. 2012. Multiple roles of class I HDACs in proliferation, differentiation, and development. Cell Mol Life Sci 69: 2173-2187.

Robinson G, Parker M, Kranenburg TA, Lu C, Chen X, Ding L, Phoenix TN, Hedlund E, Wei L, Zhu X, et al. 2012. Novel mutations target distinct subgroups of medulloblastoma. Nature 488: 43-48.

Roesch A, Becker B, Schneider-Brachert W, Hagen I, Landthaler M, Vogt T. 2006. Re-expression of the retinoblastoma-binding protein 2-homolog 1 reveals tumor-suppressive functions in highly metastatic melanoma cells. J Invest Dermatol 126: 1850-1859.

Roesch A, Mueller AM, Stempfl T, Moehle C, Landthaler M, Vogt T. 2008. RBP2-H1/JARID1B is a transcriptional regulator with a tumor suppressive potential in melanoma cells. Int J Cancer 122: 1047-1057.

Rosenthal F, Feijs KL, Frugier E, Bonalli M, Forst AH, Imhof R, Winkler HC, Fischer D, Caflisch A, Hassa PO, et al. 2013. Macrodomain-containing proteins are new mono-ADP-ribosylhydrolases. Nat Struct Mol Biol 20: 502-507.

Rossetto D, Avvakumov N, Côté J. 2012. Histone phosphorylation: A chromatin modification involved in diverse nuclear events. Epigenetics 7: $1098-1108$.

Ruthenburg AJ, Li H, Patel DJ, Allis CD. 2007. Multivalent engagement of chromatin modifications by linked binding modules. Nat Rev Mol Cell Biol 8: 983-994.

Saeed S, Logie C, Francoijs KJ, Frige G, Romanenghi M, Nielsen FG, Raats L, Shahhoseini M, Huynen M, Altucci L, et al. 2012. Chromatin accessibility, p300, and histone acetylation define PML-RAR $\alpha$ and AML1-ETO binding sites in acute myeloid leukemia. Blood 120: $3058-3068$

Sakabe K, Wang Z, Hart GW. 2010. $\beta$-N-acetylglucosamine (O-GlcNAc) is part of the histone code. Proc Natl Acad Sci 107: 19915-19920.

Sandberg ML, Sutton SE, Pletcher MT, Wiltshire T, Tarantino LM, Hogenesch JB, Cooke MP. 2005. c-Myb and p300 regulate hematopoietic stem cell proliferation and differentiation. Dev Cell 8: 153-166. 
* Schaefer U. 2014. Pharmacological inhibition of bromodomain-containing proteins in inflammation. Cold Spring Harb Perspect Biol 6: a018671.

Schenk T, Chen WC, Göllner S, Howell L, Jin L, Hebestreit K, Klein HU, Popescu AC, Burnett A, Mills K, et al. 2012. Inhibition of the LSD1 (KDM1A) demethylase reactivates the all-trans-retinoic acid differentiation pathway in acute myeloid leukemia. Nat Med 18: $605-611$.

Schreiber SLB, Bradley E. 2002. Signaling network model of chromatin. Cell Cycle 111: 771-778.

Schulte JH, Lim S, Schramm A, Friedrichs N, Koster J, Versteeg R, Ora I, Pajtler K, Klein-Hitpass L, Kuhfittig-Kulle S, et al. 2009. Lysine-specific demethylase 1 is strongly expressed in poorly differentiated neuroblastoma: Implications for therapy. Cancer Res 69: 2065-2071.

Sebastian C, Zwaans BM, Silberman DM, Gymrek M, Goren A, Zhong L, Ram O, Truelove J, Guimaraes AR, Toiber D, et al. 2012. The histone deacetylase SIRT6 is a tumor suppressor that controls cancer metabolism. Cell 151: 1185-1199.

Seligson DB, Horvath S, Shi T, Yu H, Tze S, Grunstein M, Kurdistani SK. 2005. Global histone modification patterns predict risk of prostate cancer recurrence. Nature 435: 1262-1266.

Seligson DB, Horvath S, McBrian MA, Mah V, Yu H, Tze S, Wang Q, Chia D, Goodglick L, Kurdistani SK. 2009. Global levels of histone modifications predict prognosis in different cancers. Am J Pathol 174: 16191628.

Sen N, Kumari R, Singh MI, Das S. 2013. HDAC5, a key component in temporal regulation of p53-mediated transactivation in response to genotoxic stress. Mol Cell 52: 406-420.

Serrano L, Martinez-Redondo P, Marazuela-Duque A, Vazquez BN, Dooley SJ, Voigt P, Beck DB, Kane-Goldsmith N, Tong Q, Rabanal RM, et al. 2013. The tumor suppressor SirT2 regulates cell cycle progression and genome stability by modulating the mitotic deposition of H4K20 methylation. Genes Dev 27: 639-653.

* Seto E, Yoshida M. 2014. Erasers of histone acetylation: The histone deacetylase enzymes. Cold Spring Harb Perspect Biol 6: a018713.

Shah BD, Martin P, Sotomayor EM. 2012. Mantle cell lymphoma: A clinically heterogeneous disease in need of tailored approaches. Cancer Control 19: 227-235.

Sharma SV, Lee DY, Li B, Quinlan MP, Takahashi F, Maheswaran S, McDermott U, Azizian N, Zou L, Fischbach MA, et al. 2010. A chromatin-mediated reversible drug-tolerant state in cancer cell subpopulations. Cell 141: 69-80.

Sharma P, Azebi S, England P, Christensen T, Møller-Larsen A, Petersen T, Batsché E, Muchardt C. 2012. Citrullination of histone H3 interferes with HP1-mediated transcriptional repression. PLoS Genet 8: e1002934.

Shen H, Laird PW. 2013. Interplay between the cancer genome and epigenome. Cell 153: 38-55.

* Shi YG, Tsukada Y. 2013. The discovery of histone demethylases. Cold Spring Harb Perspect Biol 5: a017947.

Shi X, Kachirskaia I, Yamaguchi H, West LE, Wen H, Wang EW, Dutta S, Appella E, Gozani O. 2007. Modulation of p53 function by SET8mediated methylation at lysine 382. Mol Cell 27: 636-646.

Smith E, Lin C, Shilatifard A. 2011. The super elongation complex (SEC) and MLL in development and disease. Genes Dev 25: 661-672.

Stewart MD, Li J, Wong J. 2005. Relationship between histone H3 lysine 9 methylation, transcription repression, and heterochromatin protein 1 recruitment. Mol Cell Biol 25: 2525-2538.

Struhl K. 1998. Histone acetylation and transcriptional regulatory mechanisms. Genes Dev 12: 599-606.

Stunkel W, Campbell RM. 2011. Sirtuin 1 (SIRT1): The misunderstood HDAC. J Biomol Screen 16: 1153-1169.

Subramanian K, Jia D, Kapoor-Vazirani P, Powell DR, Collins RE, Sharma D, Peng J, Cheng X, Vertino PM. 2008. Regulation of estrogen receptor $\alpha$ by the SET7 lysine methyltransferase. Mol Cell 30: 336-347.

Suganuma T, Workman JL. 2008. Crosstalk among histone modifications. Cell 135: 604-607.
Suva ML, Riggi N, Janiszewska M, Radovanovic I, Provero P, Stehle JC, Baumer K, Le Bitoux MA, Marino D, Cironi L, et al. 2009. EZH2 is essential for glioblastoma cancer stem cell maintenance. Cancer Res 69: 9211-9218.

Takawa M, Cho HS, Hayami S, Toyokawa G, Kogure M, Yamane Y, Iwai Y, Maejima K, Ueda K, Masuda A, et al. 2012. Histone lysine methyltransferase SETD8 promotes carcinogenesis by deregulating PCNA expression. Cancer Res 72: 3217-3227.

Tan M, Luo H, Lee S, Jin F, Yang JS, Montellier E, Buchou T, Cheng Z, Rousseaux S, Rajagopal N, et al. 2011. Identification of 67 histone marks and histone lysine crotonylation as a new type of histone modification. Cell 146: 1016-1028.

Tang J, Cho NW, Cui G, Manion EM, Shanbhag NM, Botuyan MV, Mer G, Greenberg RA. 2013. Acetylation limits 53BP1 association with damaged chromatin to promote homologous recombination. Nat Struct Mol Biol 20: 317-325.

Tanikawa C, Espinosa M, Suzuki A, Masuda K, Yamamoto K, Tsuchiya E, Ueda K, Daigo Y, Nakamura Y, Matsuda K. 2012. Regulation of histone modification and chromatin structure by the p53-PADI4 pathway. Nat Commun 3: 676.

Trojer P, Cao AR, Gao Z, Li Y, Zhang J, Xu X, Li G, Losson R, ErdjumentBromage H, Tempst P, et al. 2011. L3MBTL2 protein acts in concert with $\mathrm{PcG}$ protein-mediated monoubiquitination of $\mathrm{H} 2 \mathrm{~A}$ to establish a repressive chromatin structure. Mol Cell 42: 438-450.

Tsai MC, Wang JK, Chang HY. 2010. Tumor suppression by the histone demethylase UTX. Cell Cycle 9: 2043-2044.

Tweedie-Cullen RY, Brunner AM, Grossmann J, Mohanna S, Sichau D, Nanni P, Panse C, Mansuy IM. 2012. Identification of combinatorial patterns of post-translational modifications on individual histones in the mouse brain. PLoS One 7: e36980.

Uemura M, Yamamoto H, Takemasa I, Mimori K, Hemmi H, Mizushima T, Ikeda M, Sekimoto M, Matsuura N, Doki Y, et al. 2010. Jumonji domain containing $1 \mathrm{~A}$ is a novel prognostic marker for colorectal cancer: In vivo identification from hypoxic tumor cells. Clin Cancer Res 16: 4636-4646.

Van Aller GS, Reynoird N, Barbash O, Huddleston M, Liu S, Zmoos AF, McDevitt P, Sinnamon R, Le B, Mas G, et al. 2012. Smyd3 regulates cancer cell phenotypes and catalyzes histone H4 lysine 5 methylation. Epigenetics 7: 340-343.

Van Damme M, Crompot E, Meuleman N, Mineur P, Bron D, Lagneaux L, Stamatopoulos B. 2012. HDAC isoenzyme expression is deregulated in chronic lymphocytic leukemia B-cells and has a complex prognostic significance. Epigenetics 7: 1403-1412.

Venneti S, Garimella MT, Sullivan LM, Martinez D, Huse JT, Heguy A, Santi M, Thompson CB, Judkins AR. 2013. Evaluation of histone 3 lysine 27 trimethylation (H3K27me3) and enhancer of Zest 2 $(\mathrm{EZH} 2)$ in pediatric glial and glioneuronal tumors shows decreased H3K27me3 in H3F3A K27M mutant glioblastomas. Brain Pathol 23: $558-564$.

Vieira FQ, Costa-Pinheiro P, Ramalho-Carvalho J, Pereira A, Menezes FD, Antunes L, Carneiro I, Oliveira J, Henrique R, Jeronimo C. 2014. Deregulated expression of selected histone methylases and demethylases in prostate carcinoma. Endocr Relat Cancer 21: 51-61.

Vinatzer U, Gollinger M, Müllauer L, Raderer M, Chott A, Streubel B. 2008. Mucosa-associated lymphoid tissue lymphoma: Novel translocations including rearrangements of ODZ2, JMJD2C, and CNN3. Clin Cancer Res 14: 6426-6431.

Wagner KW, Alam H, Dhar SS, Giri U, Li N, Wei Y, Giri D, Cascone T, Kim $\mathrm{JH}$, Ye Y, et al. 2013. KDM2A promotes lung tumorigenesis by epigenetically enhancing ERK1/2 signaling. J Clin Invest 123: 5231-5246.

Wang Y, Wysocka J, Sayegh J, Lee YH, Perlin JR, Leonelli L, Sonbuchner LS, McDonald CH, Cook RG, Dou Y, et al. 2004. Human PAD4 regulates histone arginine methylation levels via demethylimination. Science 306: 279-283.

Wang GG, Cai L, Pasillas MP, Kamps MP. 2007. NUP98-NSD1 links H3K36 methylation to Hox-A gene activation and leukaemogenesis. Nat Cell Biol 9: 804-812. 
Wang L, Gural A, Sun XJ, Zhao X, Perna F, Huang G, Hatlen MA, Vu L, Liu F, Xu H, et al. 2011. The leukemogenicity of AML1-ETO is dependent on site-specific lysine acetylation. Science 333: 765-769.

Watanabe H, Soejima K, Yasuda H, Kawada I, Nakachi I, Yoda S, Naoki K, Ishizaka A. 2008. Deregulation of histone lysine methyltransferases contributes to oncogenic transformation of human bronchoepithelial cells. Cancer Cell Int 8: 15.

Wilson BG, Wang X, Shen X, McKenna ES, Lemieux ME, Cho YJ, Koellhoffer EC, Pomeroy SL, Orkin SH, Roberts CW. 2010. Epigenetic antagonism between polycomb and SWI/SNF complexes during oncogenic transformation. Cancer Cell 18: 316-328.

Wisniewski JR, Zougman A, Mann M. 2008. Nepsilon-formylation of lysine is a widespread post-translational modification of nuclear proteins occurring at residues involved in regulation of chromatin function. Nucleic Acids Res 36: 570-577.

Witt O, Deubzer HE, Lodrini M, Milde T, Oehme I. 2009. Targeting histone deacetylases in neuroblastoma. Curr Pharm Des 15: 436-447.

Wyce A, Ganji G, Smitheman KN, Chung CW, Korenchuk S, Bai Y, Barbash O, Le B, Craggs PD, McCabe MT, et al. 2013. BET inhibition silences expression of MYCN and BCL2 and induces cytotoxicity in neuroblastoma tumor models. PloS One 8: e72967.

Yan F, Alinari L, Lustberg ME, Martin LK, Cordero-Nieves HM, Banasavadi-Siddegowda Y, Virk S, Barnholtz-Sloan J, Bell EH, Wojton J, et al. 2014. Genetic validation of the protein arginine methyltransferase PRMT5 as a candidate therapeutic target in glioblastoma. Cancer Res 74: 1752-1765.

Yang ZQ, Imoto I, Fukuda Y, Pimkhaokham A, Shimada Y, Imamura M, Sugano S, Nakamura Y, Inazawa J. 2000. Identification of a novel gene, GASC1, within an amplicon at 9p23-24 frequently detected in esophageal cancer cell lines. Cancer Res 60: 4735-4739.

Yang P, Guo L, Duan ZJ, Tepper CG, Xue L, Chen X, Kung HJ, Gao AC, Zou JX, Chen HW. 2012. Histone methyltransferase NSD2/MMSET mediates constitutive NF- $\kappa \mathrm{B}$ signaling for cancer cell proliferation, survival, and tumor growth via a feed-forward loop. Mol Cell Biol 32: $3121-3131$.

Yap DB, Chu J, Berg T, Schapira M, Cheng SW, Moradian A, Morin RD, Mungall AJ, Meissner B, Boyle M, et al. 2011. Somatic mutations at EZH2 Y641 act dominantly through a mechanism of selectively altered PRC2 catalytic activity, to increase H3K27 trimethylation. Blood 117: 2451-2459.

Zhang H, Park SH, Pantazides BG, Karpiuk O, Warren MD, Hardy CW, Duong DM, Park SJ, Kim HS, Vassilopoulos A, et al. 2013. SIRT2 directs the replication stress response through CDK9 deacetylation. Proc Natl Acad Sci 110: 13546-13551.

Zhang Y, Chen A, Yan XM, Huang G. 2012a. Disordered epigenetic regulation in MLL-related leukemia. Int J Hematol 96: 428437.

Zhang X, Bolt M, Guertin MJ, Chen W, Zhang S, Cherrington BD, Slade DJ, Dreyton CJ, Subramanian V, Bicker KL, et al. 2012b. Peptidylarginine deiminase 2-catalyzed histone $\mathrm{H} 3$ arginine 26 citrullination facilitates estrogen receptor $\alpha$ target gene activation. Proc Natl Acad Sci 109: 13331-13336.

* Zhao Y, Garcia BA. 2014.Comprehensive catalog of currently documented histone modifications. Cold Spring Harb Persp Biol doi: 10.1101/ cshperspect.a025064.

Zhu J, Adli M, Zou JY, Verstappen G, Coyne M, Zhang X, Durham T, Miri M, Deshpande V, De Jager PL, et al. 2013. Genome-wide chromatin state transitions associated with developmental and environmental cues. Cell 152: 642-654

Zuber J, Shi J, Wang E, Rappaport AR, Herrmann H, Sison EA, Magoon D, Qi J, Blatt K, Wunderlich M, et al. 2011. RNAi screen identifies Brd4 as a therapeutic target in acute myeloid leukaemia. Nature 478: 524-528. 


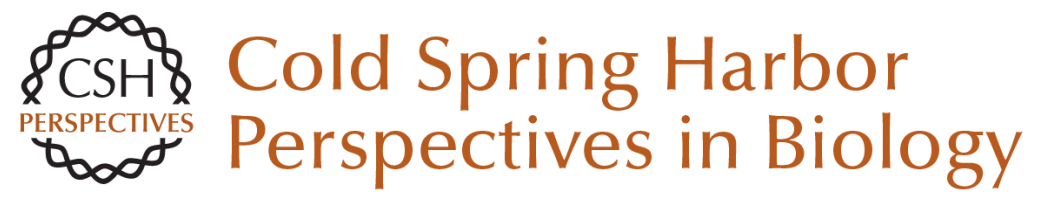

\section{Histone Modifications and Cancer}

James E. Audia and Robert M. Campbell

Cold Spring Harb Perspect Biol 2016; doi: 10.1101/cshperspect.a019521

\section{Subject Collection Epigenetics}

Metabolic Signaling to Chromatin Shelley L. Berger and Paolo Sassone-Corsi

Histone and DNA Modifications as Regulators of Neuronal Development and Function Stavros Lomvardas and Tom Maniatis

Histone Modifications and Cancer James E. Audia and Robert M. Campbell

Epigenetics and Human Disease Huda Y. Zoghbi and Arthur L. Beaudet

Induced Pluripotency and Epigenetic Reprogramming Konrad Hochedlinger and Rudolf Jaenisch

Long-Range Chromatin Interactions Job Dekker and Tom Misteli

RNAi and Heterochromatin Assembly Robert Martienssen and Danesh Moazed

Dosage Compensation in Drosophila John C. Lucchesi and Mitzi I. Kuroda
Epigenetic Determinants of Cancer Stephen B. Baylin and Peter A. Jones

Maintenance of Epigenetic Information Geneviève Almouzni and Howard Cedar

A Structural Perspective on Readout of Epigenetic Histone and DNA Methylation Marks Dinshaw J. Patel

The Necessity of Chromatin: A View in

Perspective Vincenzo Pirrotta

Germline and Pluripotent Stem Cells Wolf Reik and M. Azim Surani

Comprehensive Catalog of Currently Documented Histone Modifications Yingming Zhao and Benjamin A. Garcia

Epigenetic Regulation of Chromatin States in Schizosaccharomyces pombe Robin C. Allshire and Karl Ekwall

Histone Variants and Epigenetics Steven Henikoff and M. Mitchell Smith

For additional articles in this collection, see http://cshperspectives.cshlp.org/cgi/collection/

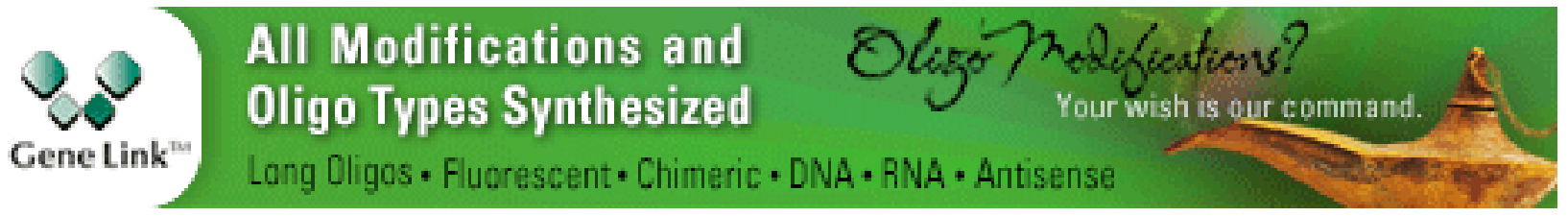

Copyright @ 2016 Cold Spring Harbor Laboratory Press; all rights reserved 
For additional articles in this collection, see http://cshperspectives.cshlp.org/cgi/collection/

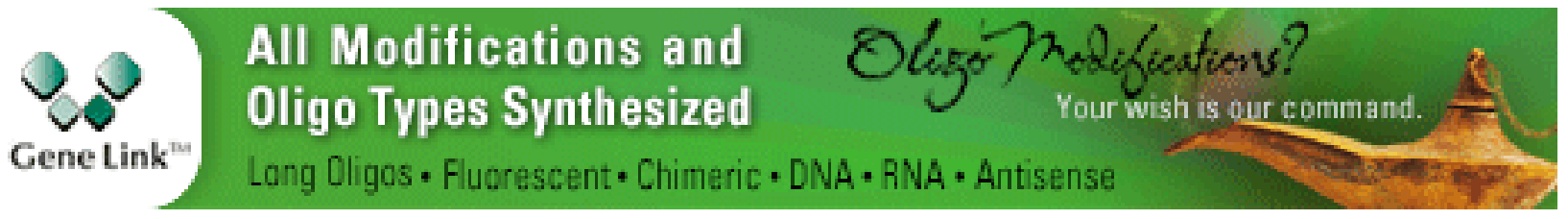

Copyright @ 2016 Cold Spring Harbor Laboratory Press; all rights reserved 